Supporting information for

\title{
Rationally Designed Protein-based Inhibitor of $\alpha$-Synuclein Fibrillization in Cells
}

Anastasiia Priss $^{1,2}$, Kseniia Afitska ${ }^{1}$, Maksym Galkin ${ }^{1,2}$, Dmytro A. Yushchenko ${ }^{1,3}$, Volodymyr V. Shvadchak ${ }^{1, *}$

${ }^{1}$ Institute of Organic Chemistry and Biochemistry, Academy of Sciences of the Czech Republic, Flemingovo nam. 2, Prague, 16610 Czech Republic;

${ }^{2}$ Department of Biochemistry, Faculty of Science, Charles University, Albertov 6, Prague, 12843, Czech Republic;

${ }^{3}$ Miltenyi Biotec GmbH, Friedrich-Ebert-Straße 68, D-51429 Bergisch Gladbach, Germany

\section{Table of contents}

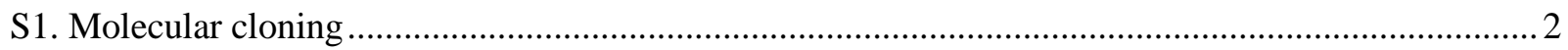

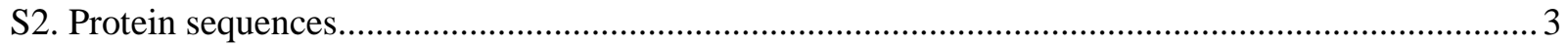

S3. Preparation of the peptide with the maleimide linker ................................................................... 4

S4. Example of the kinetic curves in seeded aggregation ................................................................. 4

S5. Bulky group position affects the activity of the inhibitor ...............................................................

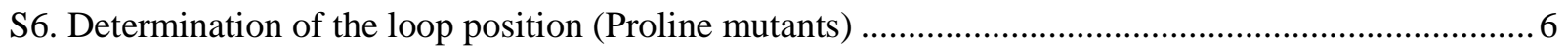

S7. Scheme of the inhibitors design and their attachment to the fibril end.......................................... 7

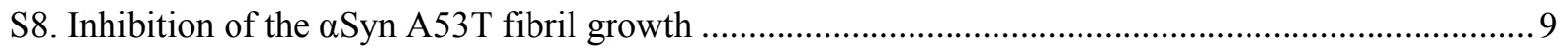

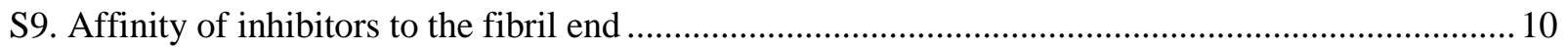

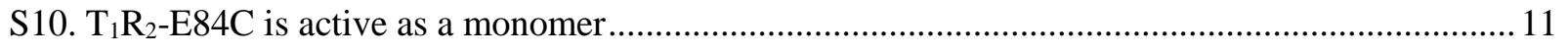

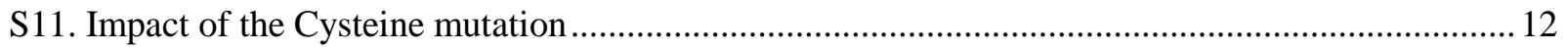

S12. Inhibitors activity in the presence of different seeds concentration............................................ 13

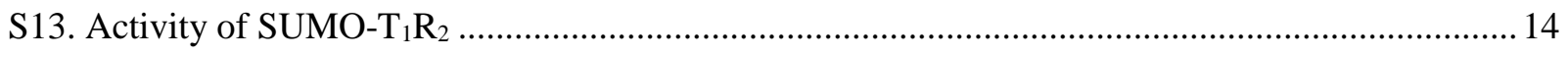

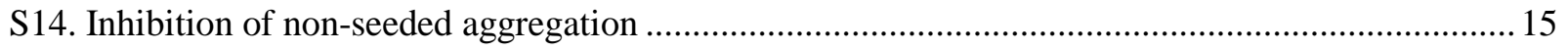

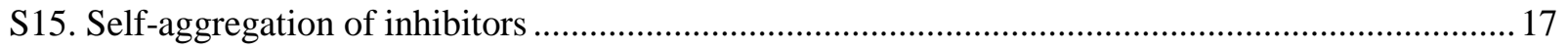

S16. Absorption and emission spectra of FRET pair dyes............................................................. 18

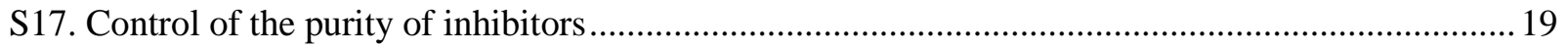

S18. Assessment of cell penetration of inhibitor and $\alpha$ Syn ...........................................................20

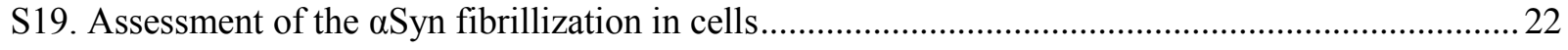




\section{S1. Molecular cloning}

Plasmid pETM11-SUMO3 was chosen as an expression vector as it contains His-tag and SUMO-tag sequences for protein purification and increase of protein solubility, respectively. After the protein expression both tags can be cleaved by SenP2 protease yielding the desirable protein. To obtain the proteins with SUMO-tag on the N-terminus (SUMO-T $R_{2}$ and SUMO- $\mathrm{T}_{1} \mathrm{R}_{2}-\mathrm{E} 84 \mathrm{C}$ ), TEV protease was used for removing His-tag.

Plasmid pT7-7-SNCA was kindly provided by Vinod Subramaniam, University of Twente. Plasmid pCR259_dL5 was kindly provided by Prof. Marcel Bruchez, Carnegie Mellon University. Plasmid pETM11-SUMO3-GFP was kindly provided by EMBL Protein Facility, Heidelberg.

All the other constructs were prepared either by site mutagenesis or by ligation of an insert and a vector, which were previously digested with appropriate restriction enzymes. After E.coli transformation with resulting constructs, positive clones were selected on kanamycin plates and used for the DNA isolation (Miniprep kit, Qiagen) and further protein expression. Correctness of constructs was confirmed by sequencing (Eurofins Genomics).

Plasmids for expression of $\alpha \mathrm{S}-\mathrm{L}$ and $\alpha \mathrm{S}-\mathrm{L}-\alpha \mathrm{S}$ were prepared by the consequent cloning of SNCA gene and L5 gene into the pETM11-SUMO3 vector.

Plasmids for expression of engineered inhibitors $\left(T_{1} T_{2}, R_{1} R_{2}\right.$ and $\left.T_{1} R_{2}\right)$ were prepared stepwise. First, nucleotide sequences corresponding to $\mathrm{T}_{1}$ or $\mathrm{R}_{1}$ fragments (aa 38-78 or 38-58 of aSyn sequence, respectively) were cloned into pETM11-SUMO3 vector. Resulting constructs were used as vectors for inserting nucleotide sequences corresponding to $T_{2}$ or $R_{2}$ fragments (aa 65-97 or 45-97 of $\alpha$ Syn sequence, respectively).

For preparation of the plasmid for expression of $T_{1} R_{2}-G 48 P / V 50 P$ mutated $R_{2}$ sequence was produced by PCR and then cloned into the vector, which contained $\mathrm{T}_{1}$ sequence. Namely, we used the same reverse primer as in the case of $\mathrm{R}_{2}$ and the following forward primer, in which two codons for Prolines are highlighted in magenta: TATATAGCTAGCAAAGAACCAGTTCCGCATGGTGTGGCA.

Several plasmids were prepared by site mutagenesis using the following primers (Table S1, mutated codons are highlighted).

Table S1. Sequences of primers used for site mutagenesis

\begin{tabular}{|l|l|l|}
\hline Resulting construct & Primers \\
\hline $\mathrm{T}_{1} \mathrm{R}_{2}$-A41P/A43P & Forward & CGGGTGTGACACCAGTACCCGCTAGCAAG \\
\cline { 2 - 3 } & Reverse & CTTGCTAGCGGGTACTGGTGTCACACCCG \\
\hline $\mathrm{T}_{1} \mathrm{R}_{2}$-G33A & Forward & AAATGTTGGAGCAGCAGTGGTGAC \\
\cline { 2 - 3 } $\mathrm{T}_{1} \mathrm{R}_{3} \mathrm{R}_{2}$-G33A & Reverse & GTCACCACTGCTGCTCCAACATTT \\
\hline $\mathrm{T}_{1} \mathrm{R}_{2}$-E84C, $\mathrm{R}_{1} \mathrm{R}_{2}$-E66C,, & Forward & TAGCCCAGAAGACAGTGTGTGGAGCAGGGAGCATTG \\
\cline { 2 - 3 } $\mathrm{T}_{1} \mathrm{~T}_{2}$-E64C & Reverse & CAATGCTCCCTGCTCCACACACTGTCTTCTGGGCTA \\
\hline
\end{tabular}




\section{S2. Protein sequences}

Table S2. Sequences of proteins used in the work

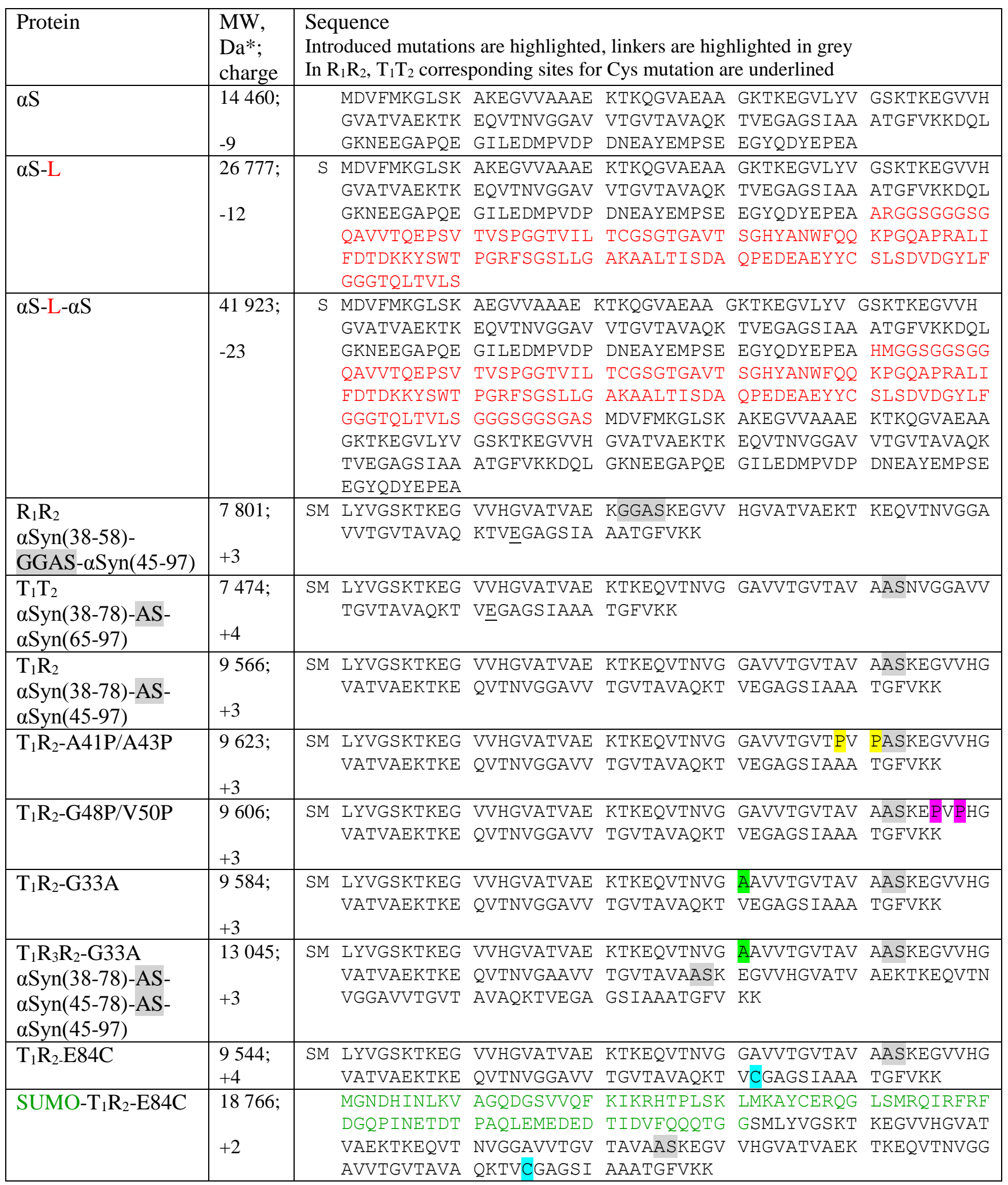

*Molecular weights are results of MALDI-TOF mass-spectrometry analysis. 


\section{S3. Preparation of the peptide with the maleimide linker}

The Maleimide-GVATVAEKTKEW peptide was prepared by the peptide synthesis facility of the Institute of Organic Chemistry and Biochemistry Prague. Its sequence corresponds to $\alpha$ Syn (51-61) with additional tryptophan residue on the C-terminus introduced to simplify measurements of the concentration.

Briefly, the peptide was synthesized at a $0.1 \mathrm{mmole}$ scale using the standard fluorenylmethoxycarbonyl (Fmoc)-amino acid-coupling protocol starting from amid resin. After coupling of the last amino acid, Fmocdeprotected peptidylresin was acylated with 4-maleimidobutiric acid.

Cleavage of the peptidyl-resin and deprotection was performed for $2 \mathrm{~h}$ using a $10 \mathrm{ml}$ trifluoroacetic acid (TFA) solution containing triisopropylsilane $(2.5 \%, \mathrm{v} / \mathrm{v})$. Solution was concentrated in vacuo and the peptide precipitated using ice-cold $\mathrm{Et}_{2} \mathrm{O}$ and pelleted by centrifugation. The pellet was then washed with $\mathrm{Et}_{2} \mathrm{O}$ and dried before solubilization with aqueous TFA $(0.05 \%, \mathrm{v} / \mathrm{v})$. Purification by HPLC was carried out on a C8 column with a linear gradient 10 to $70 \%$ B in 30 min. Purity of peptide was checked by LCMS (expected 1482, obtained $1482.8(\mathrm{M}+\mathrm{H}), 1505(\mathrm{M}+\mathrm{Na}))$

\section{S4. Example of the kinetic curves in seeded aggregation}

$\mathrm{IC}_{50}$ of fibril growth inhibition was determined from kinetic curves of seeded $50 \mu \mathrm{M} \alpha$ Syn aggregation in the absence and in the presence of inhibitors. Kinetic curves obtained from plate reader were plotted and analysed using Origin software. In Fig. S1A we present typical kinetic curves.

For calculating fibril growth rate, we used time interval between $2500 \mathrm{~s}$ and $10000 \mathrm{~s}$ (black dashed rectangle at Fig. S1A, B). At this time interval, the fluorescence intensity increases almost linearly because the fibrillized protein fraction is low and the monomer concentration is almost equal to the initial one. (The first $2500 \mathrm{~s}$ were omitted to discard short period of establishing the equilibrium temperature of the sample). However, other time intervals (e.g., 15000-25000 s, red dashed rectangle at Fig. S1A, B) of the linear period of aggregation could be used with no significant impact on the resulting data (Fig. S1C). For each sample relative fibril growth rates were calculated and normalized on the growth rate of the sample without inhibitor. Obtained average relative fibril growth rates were plotted as a function of inhibitor concentration (Fig. S1C). $\mathrm{IC}_{50}$ was determined as the concentration of inhibitor that led to the $50 \%$ decrease of the fibril growth rate (intersection of the dashed lines on the Fig. S1C).

A

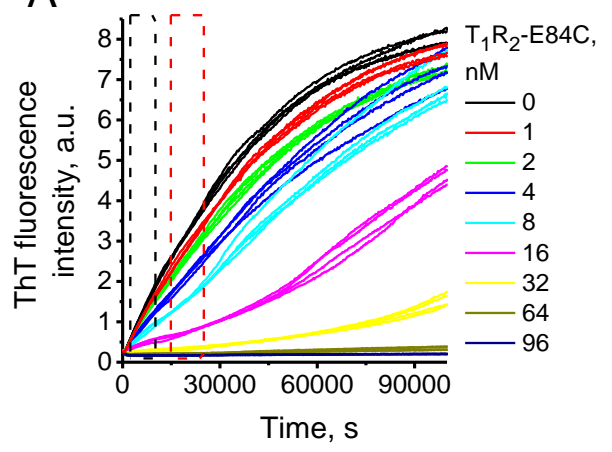

B

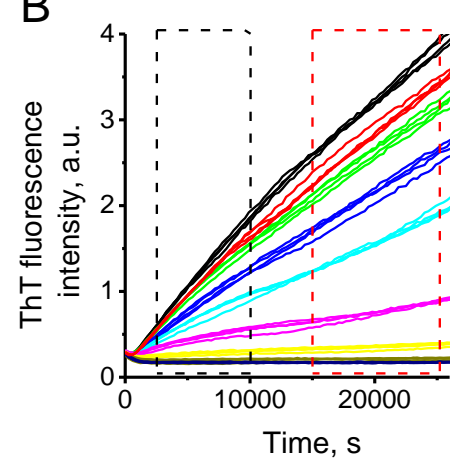

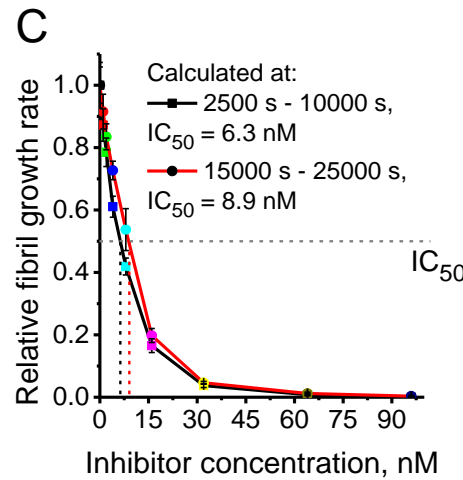

Fig. S1. A) Kinetic curves of aggregation of $50 \mu \mathrm{M} \alpha \mathrm{Syn}$ in the presence of $0.5 \mu \mathrm{M}$ seeds and different concentrations of $T_{1} R_{2}-E 84 C$ inhibitor. B) Enlarged part of the panel A. C) Relative fibril growth rates, calculated from the regions highlighted on panels A and B. 


\section{S5. Bulky group position affects the activity of the inhibitor}

Earlier we have designed $\alpha \mathrm{S}-\mathrm{L}$ inhibitor of $\alpha$ Syn fibril growth that consists of two parts: $\alpha$ Syn moiety that specifically interacts with the fibril end, and a bulky group moiety that provides steric hindrance and protects the fibril end from further monomer binding. We assumed that while $\alpha$ Syn moiety interacts with one filament on the fibril end, a bulky group forms some additional contacts with the second filament ${ }^{1}$.

We aimed to further enhance the efficiency of this inhibitor by the introduction of the second $\alpha$ Syn moiety into the inhibitor sequence. In the resulting $\alpha \mathrm{S}-\mathrm{L}-\alpha \mathrm{S}$ inhibitor molecule, two flanking $\alpha$ Syn moieties ensure binding to both filaments of the fibril (Fig. S2A). The bulky group L is in the middle of the inhibitor's sequence, therefore, upon inhibitor's binding to the fibril end the bulky group will be situated near the center of the fibril core. $\alpha \mathrm{S}-\mathrm{L}-\alpha \mathrm{S}$ shows better fibril growth inhibition efficiency than parent $\alpha \mathrm{S}-\mathrm{L}$ $\left(\mathrm{IC}_{50}=395 \pm 35 \mathrm{nM}\right.$ and $760 \pm 110 \mathrm{nM}$, respectively, Fig. S2B $)$.
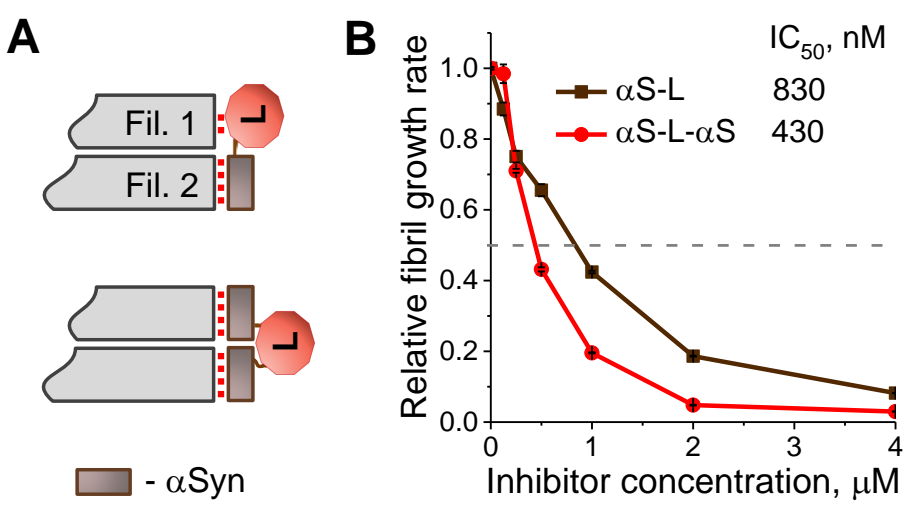

Figure S2. A) Schematic representation of a fibril with the end blocked by $\alpha \mathrm{S}-\mathrm{L}$ and $\alpha \mathrm{S}-\mathrm{L}-\alpha \mathrm{S}$. B) Relative fibril growth rate as a function of inhibitor concentration. $\alpha$ Syn and seeds concentrations were 50 and $0.5 \mu \mathrm{M}$, respectively. Error bars show SD of 4 repeats. 


\section{S6. Determination of the loop position (Proline mutants)}

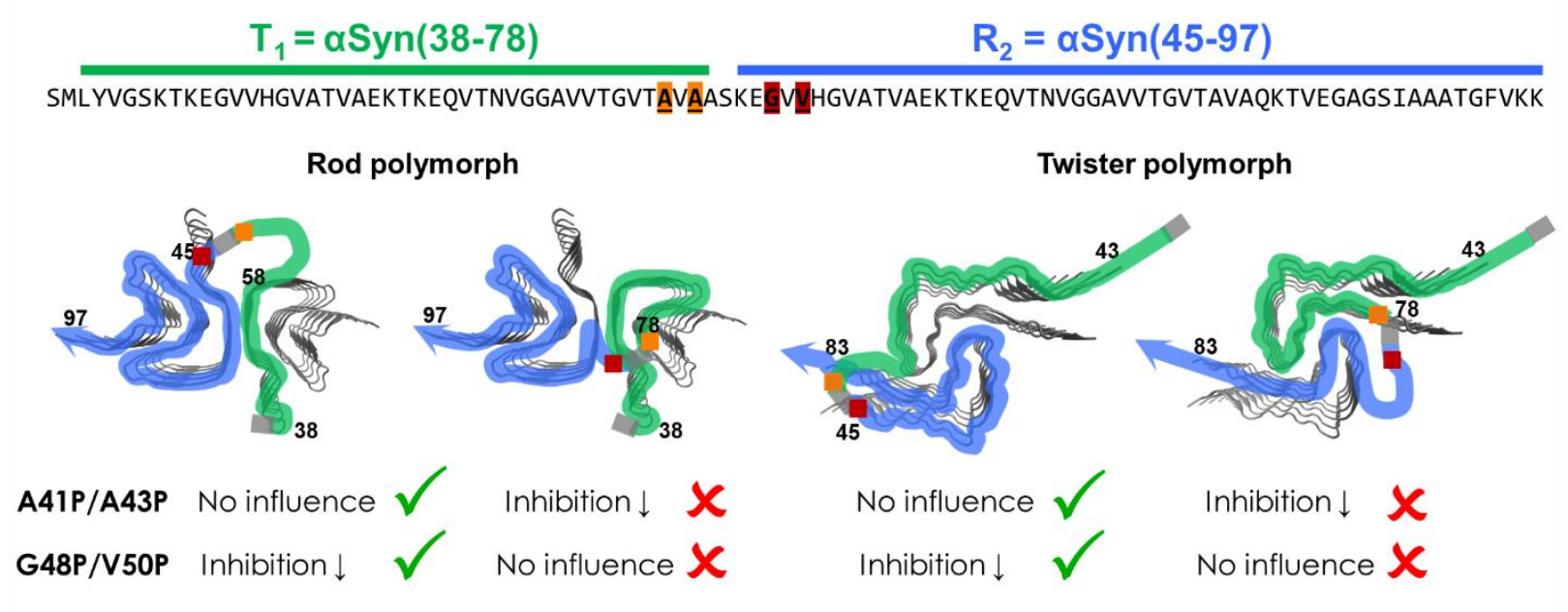

Fig. S3. Schematic representation of the $T_{1} R_{2}$ inhibitor attachment to the fibril end in two possible conformations for rod and twister fibril polymorphs. Positions of the two Proline mutations in aa 41 and 43 of $T_{1} R_{2}$ are marked with the orange square, in aa 48 and 50 - with the vine square. $\alpha$ Syn fibril is in grey. The numbers show positions of the aa residues of $\alpha$ Syn at the fibril end. The binding mode with a tight binding of the $48^{\text {th }}-50^{\text {th }}$ aa of $T_{1} R_{2}$ to the fibril core is supported by the inhibition activity experiments shown in Fig. 3. 


\section{S7. Scheme of the inhibitors design and their attachment to the fibril end}

We expect the interaction between the identical fragments of $\alpha$ Syn and inhibitor sequences if it is sterically allowed. Inhibitor $R_{1} R_{2}$ was constructed to efficiently bind to the fibril end of the rod polymorph and the majority of its amino acids (93\%, Table S3) can attach to the corresponding residues of $\alpha$ Syn at the fibril end (Fig. S4, top left). Its binding to the twister fibril polymorph is much less efficient because in this case two filaments contact at different amino acids and the central part of the inhibitor does not match the $\alpha$ Syn sequence at the contact site (Fig. S4, left bottom). On the contrary, $\mathrm{T}_{1} \mathrm{~T}_{2}$ should preferably bind to the twister polymorph. $T_{1} R_{2}$ contains additional $20 \mathrm{aa}$ in the center that provide more structural flexibility and allow it to bind efficiently to the both polymorphs forming sufficient number of H-bonds (Table S3).
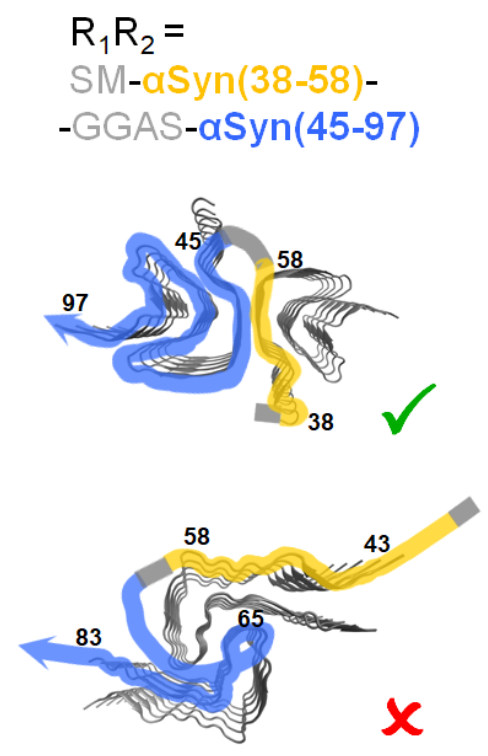
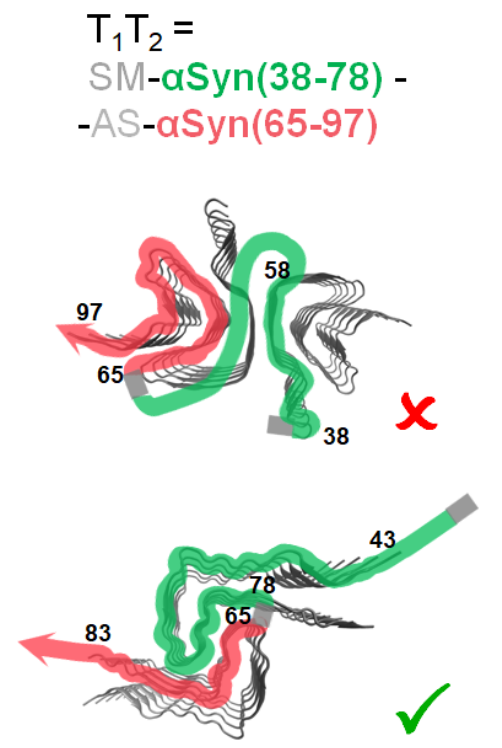

$$
\begin{aligned}
& T_{1} R_{2}= \\
& S M-a S y n(38-78)- \\
& \text {-AS-aSyn(45-97) }
\end{aligned}
$$
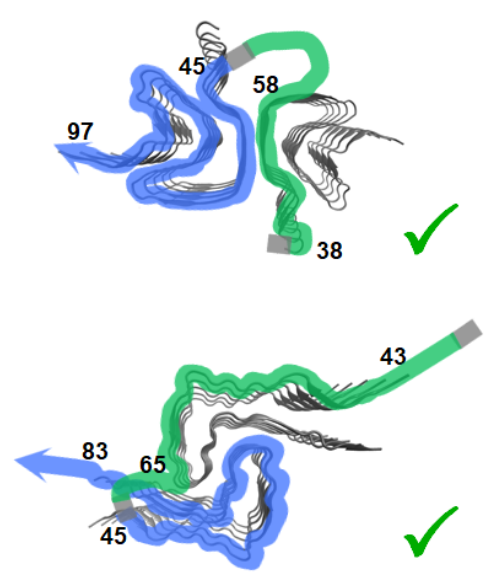

Fig. S4. Schematic representation of the inhibitors' attachment to the both filaments of the fibril end. Rod fibril polymorph is shown on the top and twister - on the bottom. $\alpha$ Syn fibril is in grey. The numbers show

\begin{tabular}{|c|c|c|c|c|}
\hline \multirow[b]{2}{*}{ Protein } & \multicolumn{2}{|c|}{$\begin{array}{c}\text { Binding to the both filaments of the } \\
\text { fibril end }\end{array}$} & \multicolumn{2}{|c|}{$\begin{array}{c}\text { Binding to a single filament of the fibril } \\
\text { end }\end{array}$} \\
\hline & Rod polymorph & Twister polymorph & Rod polymorph & Twister polymorph \\
\hline $\mathrm{R}_{1} \mathrm{R}_{2}$ (80 aa res) & $74(93 \%$ of seq) & $35(44 \%$ of seq) & $58(73 \%$ of seq) & $38(48 \%$ of seq) \\
\hline $\mathrm{T}_{1} \mathrm{~T}_{2}$ (78 aa res) & $48(62 \%$ of seq) & $55(70 \%$ of seq) & $57(73 \%$ of seq) & $38(49 \%$ of seq) \\
\hline $\mathrm{T}_{1} \mathrm{R}_{2}$ (98 aa res) & $74(76 \%$ of seq) & $60(61 \%$ of seq $)$ & $55(56 \%$ of seq) & $38(39 \%$ of seq) \\
\hline$\alpha$ Syn & - & - & $60(43 \% \text { of seq })^{2}$ & $41(29 \%$ of seq) \\
\hline
\end{tabular}
positions of aa residues of $\alpha$ Syn at the fibril end. Target polymorphs are marked with check mark.

Table S3. Number of H-bonds formed between the inhibitor and fibril end

We expect that the inhibitors interact with the both filaments at the fibril end. Alternative binding to only one filament is much less energetically efficient because it provides less hydrogen bonds per inhibitor molecule (Fig. S5). Namely, $\mathrm{R}_{1} \mathrm{R}_{2}$ upon binding to the both filaments can form $74 \mathrm{H}$-bonds with the fibril end of a rod polymorph, while its binding to one filament cannot be supported by more than $58 \mathrm{H}$-bonds because the length of the whole $\beta$-sheet domain of one $\alpha$ Syn molecule is 60 aa. Similarly, binding to only 
one filament of the fibril end, is less thermodynamically effective for all the studied inhibitors (Table S3) and should occur only in the presence of high inhibitor concentrations.

Interestingly, if $\mathrm{R}_{1} \mathrm{R}_{2}$ and $\mathrm{T}_{1} \mathrm{~T}_{2}$ interact with fibril polymorph, to which they are not specific, they form more contacts with only single filament (Table S3). However, if such binding is happening, in most cases a protein would form a loop, which would interfere with further fibril growth and, possibly, inhibit it.

$$
\begin{array}{cccc}
\mathrm{R}_{1} \mathrm{R}_{2} & \mathrm{~T}_{1} \mathrm{~T}_{2} & \mathrm{~T}_{1} \mathrm{R}_{2} & \mathrm{~T}_{1} \mathrm{R}_{2} \\
\text { Rod } & \text { Twister } & \text { Rod } & \text { Twister }
\end{array}
$$
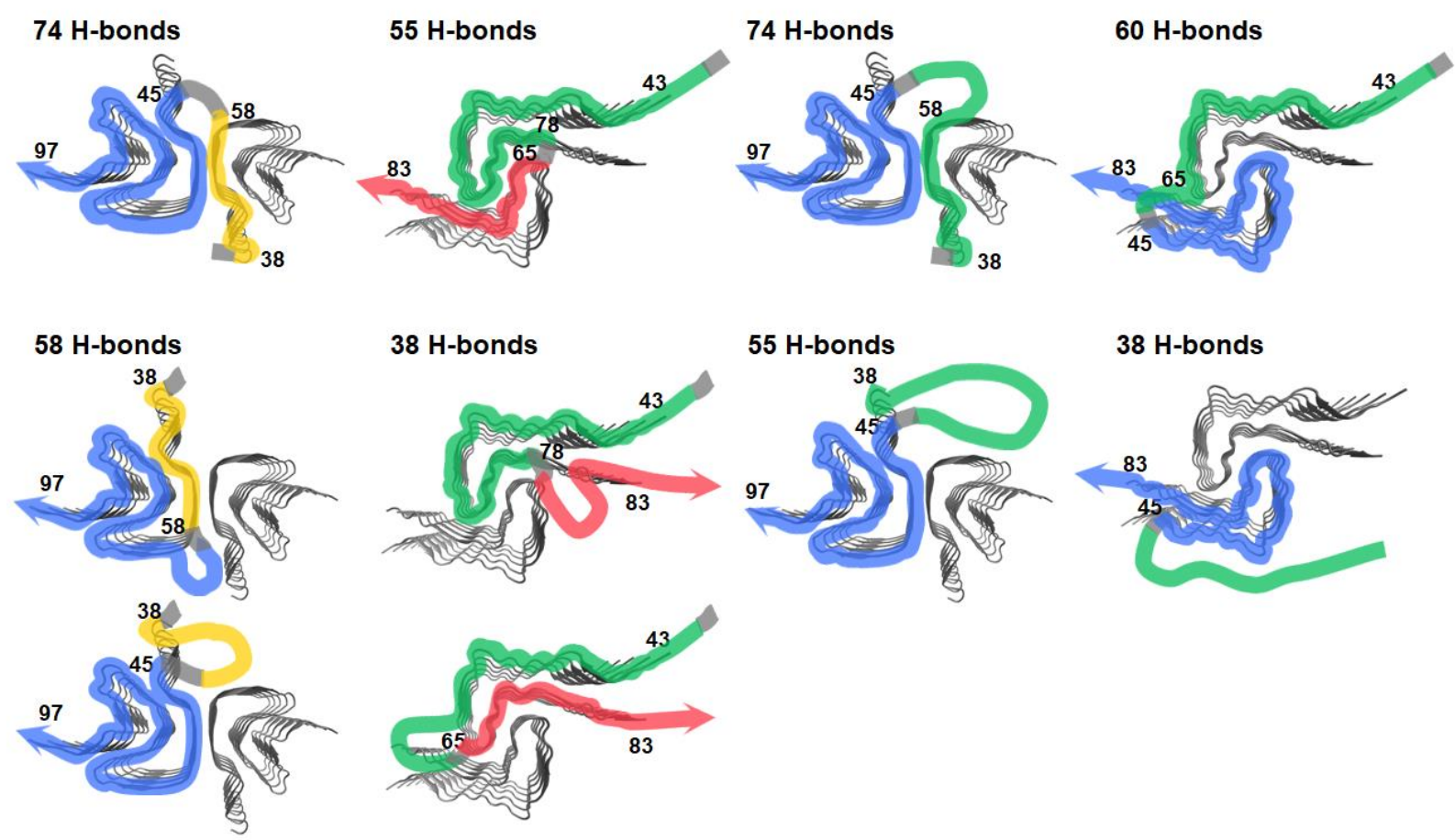

38 H-bonds
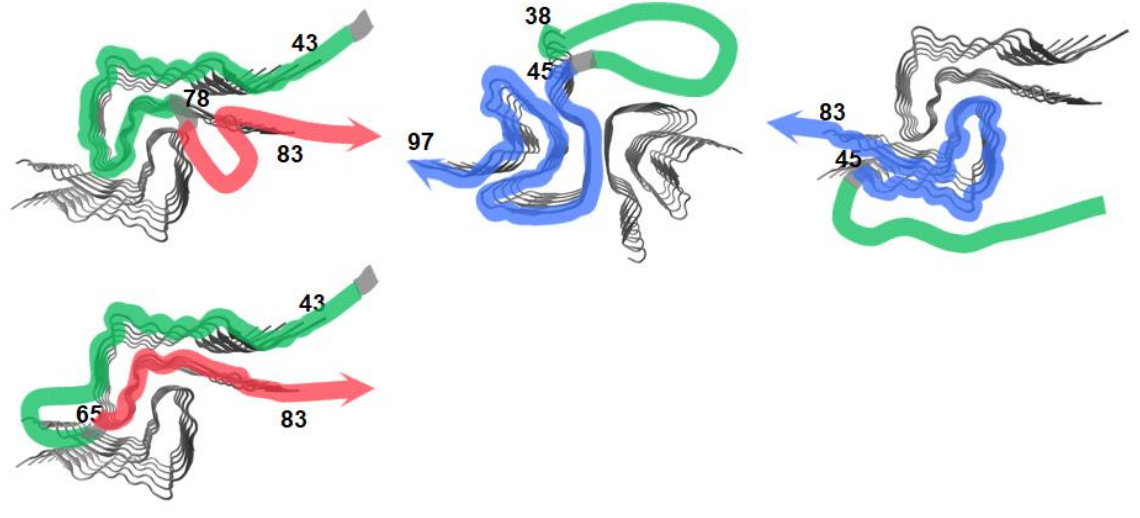

Fig. S5. Schematic representation of the inhibitors' attachment to the target fibril polymorph assuming a two-filament (top) and a single-filament (bottom) binding. aSyn fibril is in grey. The numbers show positions of the aa residues of $\alpha$ Syn at the fibril end. 


\section{S8. Inhibition of the aSyn A53T fibril growth}

Designed proteins can inhibit fibrillization not only of WT $\alpha$ Syn but also of its A53T mutant. $\mathrm{T}_{1} \mathrm{~T}_{2}$ inhibits fibrillization of A53T $\alpha$ Syn better than growth of WT $\alpha$ Syn fibrils, while $R_{1} R_{2}$ and $T_{1} R_{2}$ are more active against WT $\alpha$ Syn (Fig. S6). This difference can be a result of different fibril polymorphs formed in the case of WT and A53T $\alpha$ Syn fibrillization. The structure of the aSyn fibrils in vivo is not known, but in vitro WT $\alpha$ Syn mostly tends to form rod polymorph ${ }^{3}$, which hardly can be formed by the A53T $\alpha$ Syn that likely forms twister polymorph ${ }^{2,4}$. Higher activity of $\mathrm{T}_{1} \mathrm{~T}_{2}$ against $\alpha \mathrm{Syn}$ A53T fibrillization is therefore completely in line with its twister-oriented sequence. Activity of $\mathrm{R}_{1} \mathrm{R}_{2}$ against $A 53 \mathrm{~T}$ can be a result of its binding to the twister polymorph, or presence of other polymorphs in solution, e.g. those presented in ${ }^{5}$ and ${ }^{6}$.

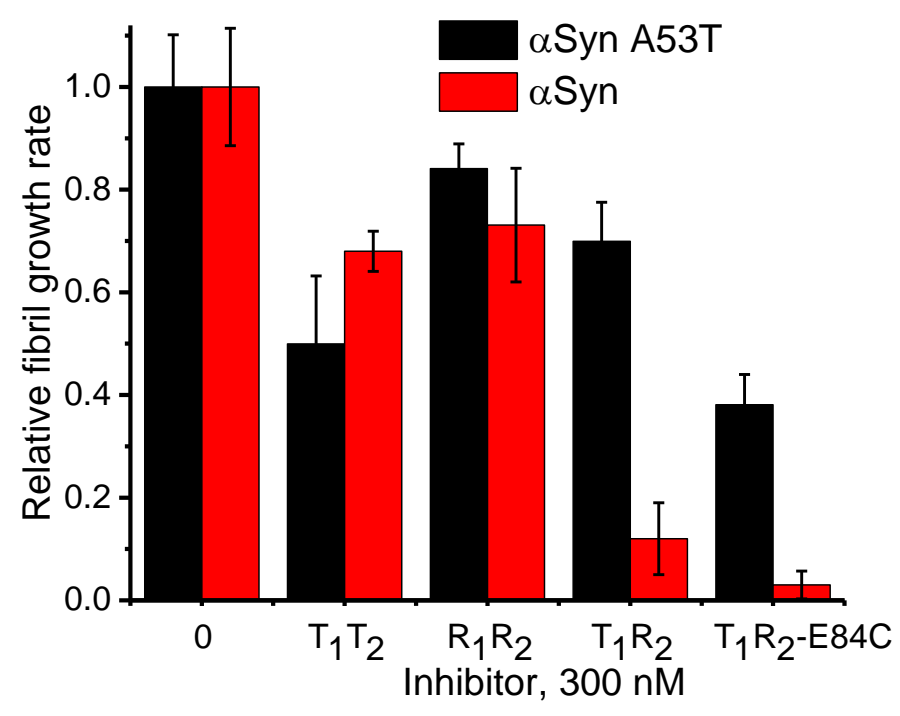

Fig. S6. Inhibition of the seeded fibrillization of $\alpha$ Syn and $\alpha$ Syn A53T. Relative fibril growth rates of $50 \mu \mathrm{M}$ proteins in the absence and in the presence of $300 \mathrm{nM}$ inhibitors. Error bars are SD of 4 repeats. 


\section{S9. Affinity of inhibitors to the fibril end}

To monitor binding of the inhibitors to $\alpha$ Syn fibrils we used fluorescence anisotropy. Upon addition of short $\alpha$ Syn fibrils $(\sim 50 \mathrm{~nm})$, fluorescence anisotropy of labeled proteins increased from $\sim 0.01$ to $\sim 0.27$ due to binding of the labeled molecules to slowly rotating species. Affinity of protein to the fibril end was calculated as described in the experimental section.
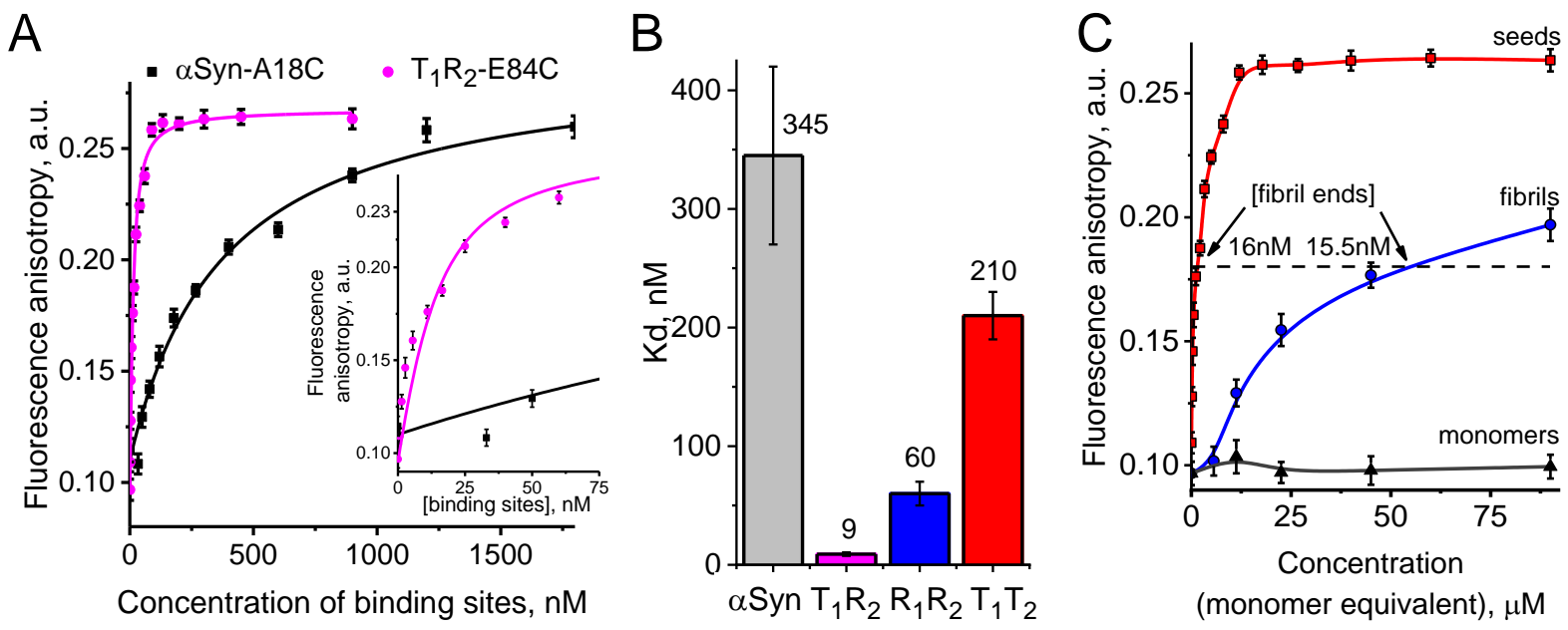

Fig. S7. Fluorescence anisotropy of labelled proteins upon interaction with short $\alpha$ Syn fibrils (seeds). Fluorescence anisotropy was measured from $10 \mathrm{nM} \alpha \mathrm{Syn}-\mathrm{A} 18 \mathrm{C}$ and $\mathrm{T}_{1} \mathrm{R}_{2}-\mathrm{E} 84 \mathrm{C} . \mathrm{K}_{\mathrm{d}}$ values (B) obtained by fitting original titration curves of fluorescence anisotropy. C) Fluorescence anisotropy of $T_{1} R_{2}-E 84 C$ $\mathrm{SRhB}(10 \mathrm{nM})$ upon interaction with $\alpha$ Syn in monomeric or fibrillar form (long fibrils and short seeds).

Calculated affinity of $\alpha$ Syn-A18C-SRhB to the ends of fibrils ( $345 \pm 75 \mathrm{nM}$ ) was in line with previously published values ${ }^{1}$. Affinity of $\mathrm{T}_{1} \mathrm{R}_{2}$-E84C-SRhB to the fibril ends was much stronger (Fig. S7A) yielding $K_{d}$ of $9 \pm 3 \mathrm{nM}$. Two other inhibitors, $R_{1} R_{2}$ and $T_{1} T_{2}$, showed intermediate affinity constants (Fig. S7B).

A high affinity of $\mathrm{T}_{1} \mathrm{R}_{2}$-E84C to the fibril end is in line with its low nanomolar $\mathrm{IC}_{50}$ (Table 1 and Fig. 4 of the main text). To check whether our assumption of the preferential binding to the fibril ends is correct, we titrated $\mathrm{T}_{1} \mathrm{R}_{2}$-E84C-SRhB with monomeric $\alpha$ Syn, long $\alpha$ Syn fibrils ( 4000 monomers in length) and short $\alpha$ Syn fibrils ( 100 monomers in length) prepared by sonication of the same batch of long fibrils. The inhibitor efficiently binds to the short fibrils as was shown in the previous experiment. Meanwhile, upon its interaction with long fibrils (Fig. S7C) the complete binding was not reached even at $90 \mu \mathrm{M}$ long fibrils, therefore, to analyze the data, we had to assume that the anisotropy of $\mathrm{T}_{1} \mathrm{R}_{2}$-E84C-SRhB bound to long fibrils reaches the same value than in the case of short fibrils $(\sim 0.27)$. 50\% binding of $\mathrm{T}_{1} \mathrm{R}_{2}$-E84C occurs in the presence of $\sim 55 \mu \mathrm{M}$ non-sonicated fibrils (Fig. S7C). Concentration of fibril ends in such solution is $\sim 16 \mathrm{nM}$ that is sufficient to bind $\sim 50 \%$ of the total inhibitor by the fibril ends (as was determined in experiment with sonicated fibrils). Therefore, if some inhibitor is bound not to the ends, but to the sides of fibrils, it is only a minor fraction out of all bound inhibitor. In other words, affinity of the $\mathrm{T}_{1} \mathrm{R}_{2}$-E84C to the fibril sides is low comparing to the binding to the fibril ends and its binding to the sides can be neglected.

In contrast to the interaction with the fibrillar form of $\alpha$ Syn, $T_{1} R_{2}$-E84C-SRhB shows almost no interaction with monomeric $\alpha$ Syn of up to $100 \mu \mathrm{M}$ concentrations, remaining selective to the misfolded protein (Fig. S7C, grey curve). 


\section{S10. $T_{1} R_{2}-E 84 C$ is active as a monomer}

In order to prove that inhibition activity of $\mathrm{T}_{1} \mathrm{R}_{2}-\mathrm{E} 84 \mathrm{C}$ is not caused by its dimerization, we performed three experiments.

The $\mathrm{T}_{1} \mathrm{R}_{2}$-E84C protein labeled with SRhB-maleimide protein cannot form disulfide dimer. Meanwhile its activity was only slightly lower than activity of $T_{1} R_{2}$-E84C and significantly higher than of $T_{1} R_{2}$ (Fig. S8A). Labelling of the $T_{1} R_{2}-E 84 C$ restored the original charge of the $T_{1} R_{2}$, but this change did not decrease its activity.

We also studied the inhibition activity of $T_{1} R_{2}$-E84C under the reducing conditions, in the presence of dithiothreitol (DTT). Activity of $\mathrm{T}_{1} \mathrm{R}_{2}$-E84C in the presence and in the absence of DTT was almost identical (Fig. S8B), clearly indicating that $\mathrm{T}_{1} \mathrm{R}_{2}$-E84C is active as a monomer.

Polyacrylamide gel-electrophoresis (PAGE) of proteins with and without another well-known reducing agent $\beta$-mercaptoethanol ( $\beta \mathrm{ME}$ ) shows that our samples of $\mathrm{T}_{1} \mathrm{R}_{2}$-E84C contain no impurity of the dimer (Fig. S8C). It also shows that the sample of $\left(\mathrm{T}_{1} \mathrm{R}_{2}-\mathrm{E} 84 \mathrm{C}\right)_{2}$ is, on contrary, free of monomer.

Another confirmation is given by the ESI mass-spectra that were recorded after preparation of $\left(T_{1} R_{2}-E 84 C\right)_{2}$ and $T_{1} R_{2}$-E84Cpep from $T_{1} R_{2}$-E84C. Obtained molecular weight was 19078 Da for $\left(T_{1} R_{2}-\right.$ $\mathrm{E} 84 \mathrm{C})_{2}$ and $11022 \mathrm{Da}$ for $\mathrm{T}_{1} \mathrm{R}_{2}$-E84Cpep, whereas for $\mathrm{T}_{1} \mathrm{R}_{2}$-E84C molecular weight was $9544 \mathrm{Da}$.
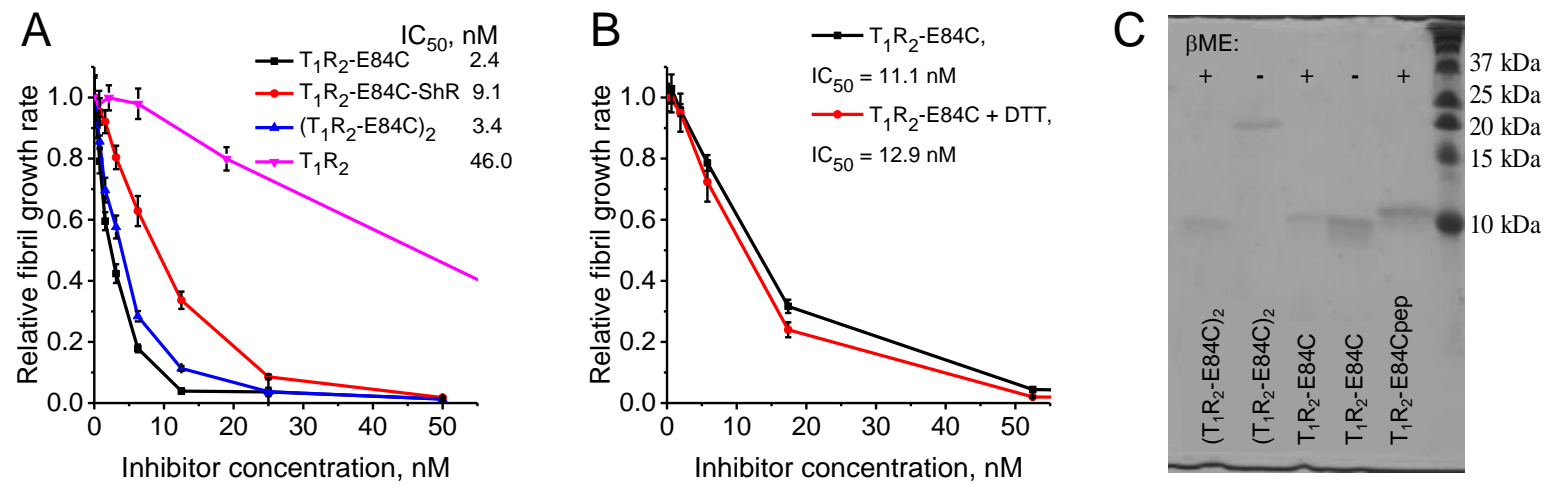

Fig. S8. A) Aggregation of $50 \mu \mathrm{M} \alpha \mathrm{Syn}$ in the presence of $0.5 \mu \mathrm{M}$ seeds and different inhibitors' concentrations. ShR marks SulfoRhodamine B label. B) Aggregation of $50 \mu \mathrm{M} \alpha \mathrm{Syn}$ in the presence of $0.5 \mu \mathrm{M}$ seeds and different concentrations of $\mathrm{T}_{1} \mathrm{R}_{2}$-E84C inhibitor. Aggregation was performed in the absence (black curve) or in the presence (red curve) of $1 \mathrm{mM}$ DTT. C) PAGE (18\% gel) of $\mathrm{T}_{1} \mathrm{R}_{2}-\mathrm{E} 84 \mathrm{C}$, $\mathrm{T}_{1} \mathrm{R}_{2}$-E84Cpep and $\left(\mathrm{T}_{1} \mathrm{R}_{2} \text {-E84C }\right)_{2}$. Samples in reducing conditions contained $2.5 \% \beta$-mercaptoethanol and are marked as $\beta \mathrm{ME}+$, samples without it are marked as $\beta \mathrm{ME}-$. 


\section{S11. Impact of the Cysteine mutation}

As the Cys mutation in the sequence of the $T_{1} R_{2}$ protein has a significant influence on its inhibition activity, we decided to check the effect of the equivalent mutation on two other our inhibitors $-\mathrm{T}_{1} \mathrm{~T}_{2}$ and $R_{1} R_{2}$. Using the same pair of primers as for the $T_{1} R_{2}-E 84 C$ production, we prepared $T_{1} T_{2}-E 64 C$ and $R_{1} R_{2}-$ E66C proteins and tested their inhibition activity under the reducing conditions (DTT was present in the buffer). The positions of the introduced mutations correspond to the position E83 in the $\alpha$ Syn sequence. In the rod fibril polymorph this Glutamate is located inside the fibril core, while in the twister fibril polymorph - on the edge of the fibril core (Fig. S9A).

As a fibrillization inhibitor, $R_{1} R_{2}$-E66C is about 10 -fold more active than $R_{1} R_{2}$ (Fig. $S 9 B$ ). In other words, the effect of the Cysteine mutation in $R_{1} R_{2}$ is the same as in the case of $T_{1} R_{2}$. This mutation is located in $\mathrm{R}_{2}$ subunits of the both inhibitors that are supposed to interact with the rod fibril polymorph in a similar way. In contrary, Cysteine mutation in $\mathrm{T}_{1} \mathrm{~T}_{2}$ inhibitor does not improve its inhibition efficiency (Fig. S9B) that is in line with a periphery position of the mutation in twister fibril polymorph targeted by this inhibitor.

We believe that the Cysteine mutation in this position mainly affects not the affinity of inhibitor to the fibril end, but the interface of interaction of the inhibitor with the $\alpha$ Syn monomer.
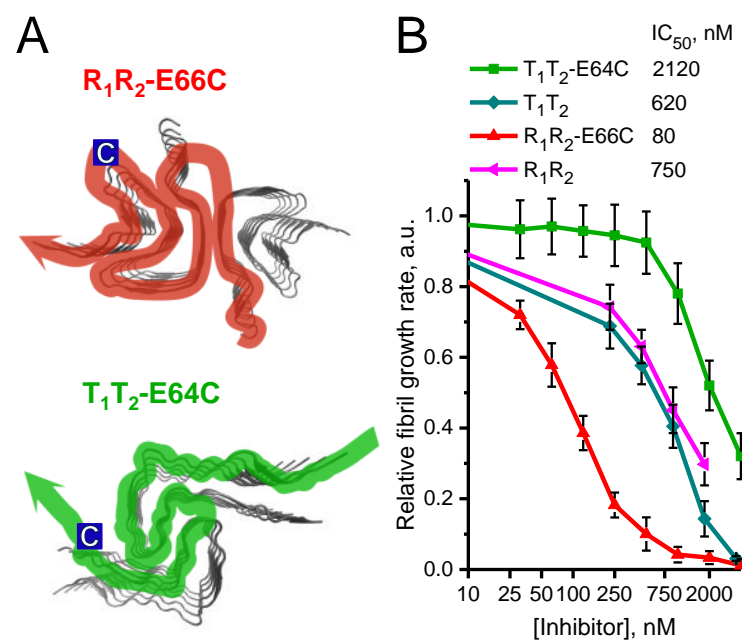

Fig. S9. A) Binding of Cysteine mutants of $T_{1} T_{2}$ and $R_{1} R_{2}$ to the fibril end, position of the mutation is marked with a blue square. B) Aggregation of $50 \mu \mathrm{M} \alpha \mathrm{Syn}$ in the presence of $1 \mathrm{mM}$ DTT, $0.5 \mu \mathrm{M}$ seeds and different concentrations of inhibitors. Error bars show SD of four repeats. 


\section{S12. Inhibitors activity in the presence of different seeds concentration}

Typical conditions of our kinetic assay for the fibril growth rate assessment include induction of the fibrillization by the $500 \mathrm{nM}$ short fibrils (seeds) that corresponds to $\sim 5 \mathrm{nM}$ concentration of fibril ends ${ }^{7}$.

Taking into account that at least one molecule of the inhibitor is needed to block the fibril end, we can expect that the observed $\mathrm{IC}_{50}$ of inhibitor cannot be lower than the concentration of fibril ends used in the experiment.

$$
\mathrm{IC}_{50} \geq \mathrm{K}_{\mathrm{d}}+\mathrm{C}_{\text {ends }} / 2 \text {, }
$$

where $\mathrm{K}_{\mathrm{d}}$ is the dissociation constant of the inhibitor-fibril end complex and $\mathrm{C}_{\text {ends }}$ is the concentration of fibril ends in the system.

In the case of inhibitors like $\mathrm{T}_{1} \mathrm{R}_{2}$-E84C with IC50 $\sim 5 \mathrm{nM}$ the amount of inhibitor bound to the fibril ends cannot be neglected and the concentration of seeds and their average length can significantly influence the measured $\mathrm{IC}_{50}$ (Fig. S10A), which varies from $2 \mathrm{nM}$ in experiments with low seeds concentration to $16 \mathrm{nM}$ when $1 \mu \mathrm{M}$ seeds were used.

In the case of less active inhibitors $\mathrm{Kd} \gg>\mathrm{C}_{\text {ends }}$ and the influence of the seed concentration is smaller (Fig. S10B). Still, reactivation of the blocked fibril end is more probable in case of the high concentrations of the fibril ends, affecting the inhibitor's $\mathrm{IC}_{50}{ }^{8}$.

A

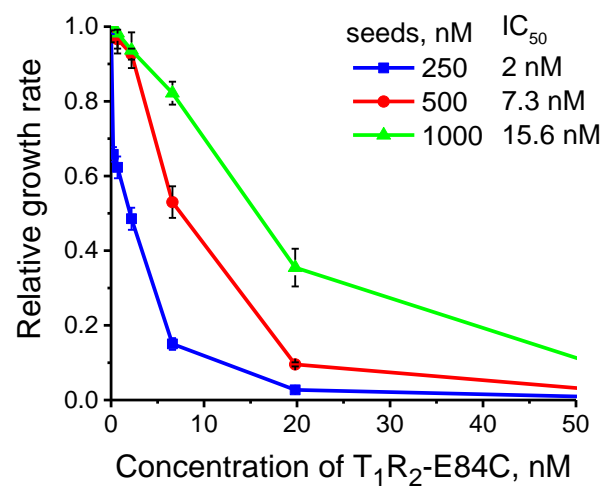

B

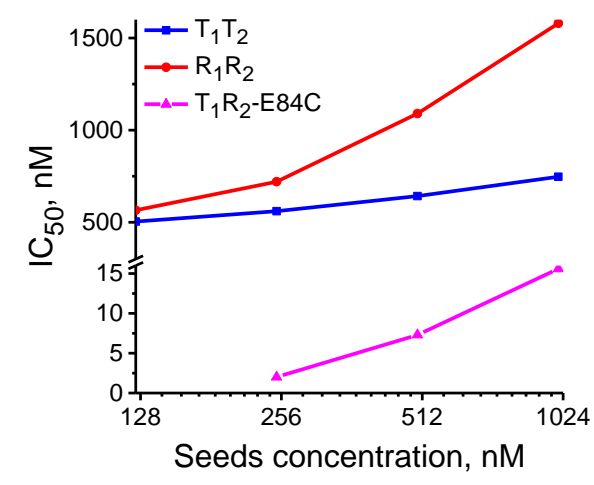

Fig. S10. A) Aggregation of $50 \mu \mathrm{M} \alpha \mathrm{Syn}$ in the presence of different seeds concentration and different concentrations of $T_{1} R_{2}$-E84C inhibitor. B) Influence of different seeds concentration on measured IC50 of $\mathrm{T}_{1} \mathrm{~T}_{2}, \mathrm{R}_{1} \mathrm{R}_{2}$ and $\mathrm{T}_{1} \mathrm{R}_{2}$-E84C inhibitors. 


\section{S13. Activity of SUMO-T $1 R_{2}$}

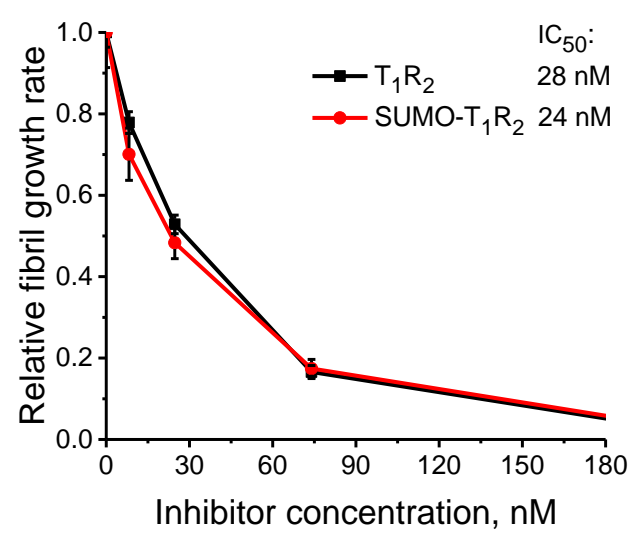

Fig. S11. Aggregation of $50 \mu \mathrm{M} \alpha \mathrm{Syn}$ in the presence of $0.5 \mu \mathrm{M}$ seeds and different concentrations of $\mathrm{T}_{1} \mathrm{R}_{2}$ and $\mathrm{SUMO}-\mathrm{T}_{1} \mathrm{R}_{2}$ inhibitor 


\section{S14. Inhibition of non-seeded aggregation}

Table S4. Delay times of the fibril formation of $100 \mu \mathrm{M} \alpha \operatorname{Syn}(\mathrm{h}) *$

\begin{tabular}{|c|r|rrrr|rrrrrrr|rrrrr|r|}
\hline & No inhibitor & \multicolumn{4}{|c|}{$\mathrm{T}_{1} \mathrm{R}_{2}, \mathrm{nM}$} & \multicolumn{4}{|c|}{$\mathrm{T}_{1} \mathrm{R}_{2}-\mathrm{E} 84, \mathrm{nM}$} & \multicolumn{4}{c|}{$\mathrm{T}_{1} \mathrm{R}_{2}$-E84Cpep, $\mathrm{nM}$} \\
$\mathrm{n}$ & & & 30 & 100 & 300 & 1000 & 10 & 30 & 100 & 300 & 1000 & 10 & 30 & 100 & 300 & 1000 \\
\hline 1 & 13.0 & 20.9 & 26.7 & 18.5 & 14.5 & 106.0 & 7.1 & 21.8 & 46.0 & 41.3 & 81.1 & 33.5 & 14.2 & 100.7 & 104.0 & 92.0 \\
2 & 16.3 & 25.5 & 23.3 & 29.0 & 16.5 & 116.3 & 8.4 & 25.0 & 46.0 & 43.9 & 96.1 & 17.2 & 28.7 & 110.0 & 132.0 & 106.4 \\
3 & 22.8 & 33.4 & 22.6 & 30.6 & 17.9 & 130.0 & 9.0 & 31.0 & 53.0 & 46.5 & 65.6 & 17.2 & 26.3 & 68.1 & 164.0 & 107.4 \\
4 & 22.5 & 13.9 & 22.3 & 32.0 & 19.3 & 34.0 & 15.0 & 37.5 & 53.0 & 48.5 & 57.1 & 18.8 & 25.5 & 61.0 & 171.0 & 110.6 \\
5 & 26.1 & 15.9 & 22.0 & 32.2 & 20.8 & 35.3 & 15.0 & 32.6 & 56.0 & 51.2 & 60.4 & 19.3 & 24.6 & 47.5 & 195.0 & 114.3 \\
6 & 28.0 & 16.6 & 16.2 & 32.6 & 24.0 & 38.5 & 17.0 & 27.5 & 64.0 & 79.8 & 70.0 & 22.1 & 21.6 & 45.3 & 207.0 & 115.0 \\
7 & 15.8 & 18.5 & 16.1 & 33.0 & 28.0 & 55.5 & 18.5 & 45.0 & 101.0 & 87.6 & 62.0 & 23.0 & 22.0 & 37.2 & 220.0 & 116.4 \\
8 & 15.7 & 18.8 & 15.5 & 59.0 & 39.5 & 71.2 & 26.0 & 53.4 & 139.0 & 10.0 & 70.3 & 24.0 & 22.3 & 35.0 & 200.0 & 138.0 \\
\hline
\end{tabular}

*Lagtime was calculated as time, when ThT fluorescence reached $2 \%$ of the maximal value that was defined as average value of ThT plateau in samples without inhibitor. Data of individual experiments used for preparation of Fig. 5A.
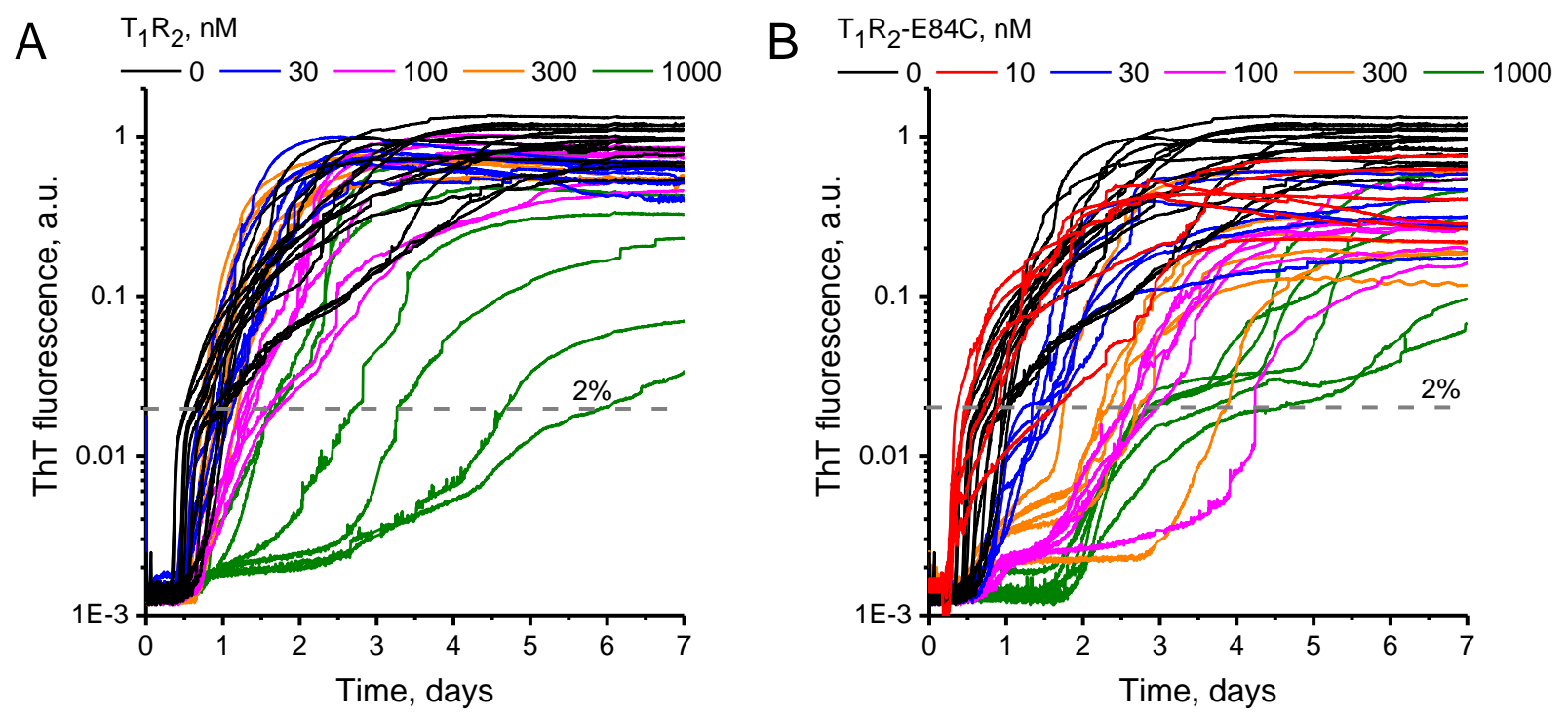

Fig. S12. Inhibition of the non-seeded aggregation of $100 \mu \mathrm{M} \alpha$ Syn by $T_{1} R_{2}$ and $T_{1} R_{2}-E 84 C$ ( 0 to $\left.1000 \mathrm{nM}\right)$. ThT kinetic curves. 8 repeats per each inhibitor concentration. In each group curves corresponding to the shortest and the longest lag time were discarded for clarity (but presented in Table S4 and other graphs). 


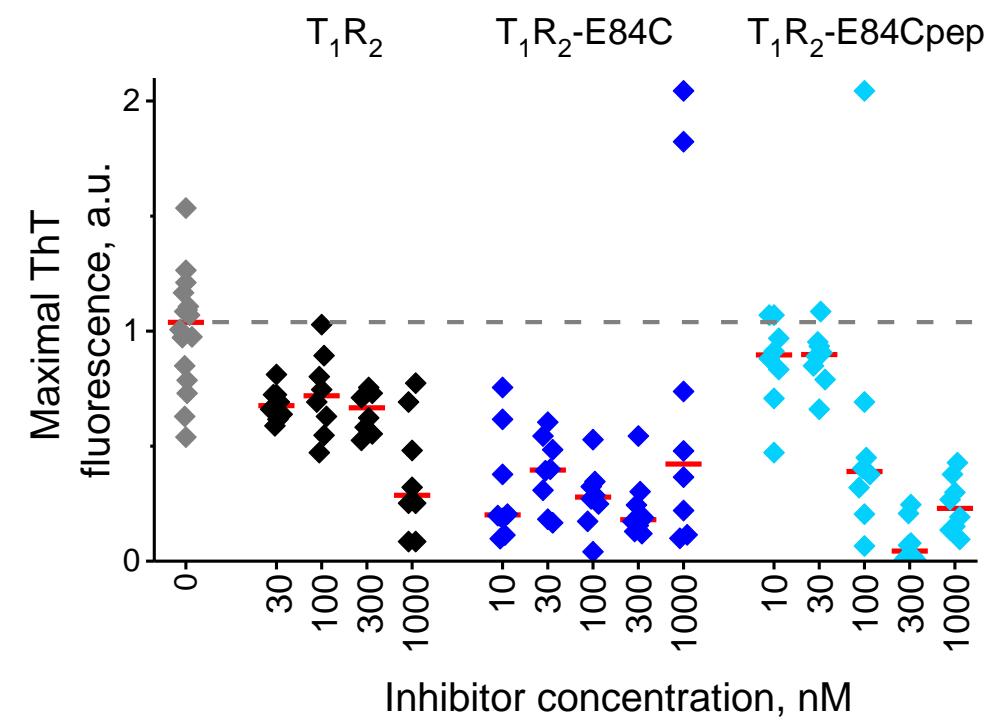

Fig. S13. Level of the ThT plateau after fibrillization of the $100 \mu \mathrm{M} \alpha \mathrm{Syn}$ in the presence of the different inhibitor concentrations. Median values are marked with red lines. 


\section{S15. Self-aggregation of inhibitors}

Inhibitors $T_{1} T_{2}, R_{1} R_{2}$, and $T_{1} R_{2}$ are constructed based on the structure of $\alpha$ Syn fibril core. They contain many aliphatic $\beta$-prone amino acids and few charged residues (14 to 18\%). Therefore, such inhibitors may self-aggregate. To assess their aggregation propensity, we induced their fibrillization by the addition of $1 \mu \mathrm{M} \alpha$ Syn seeds (Fig. S14). Kinetics of fibrillization was studied under the same conditions as used in $\alpha$ Syn aggregation experiments using ThT fluorescence.

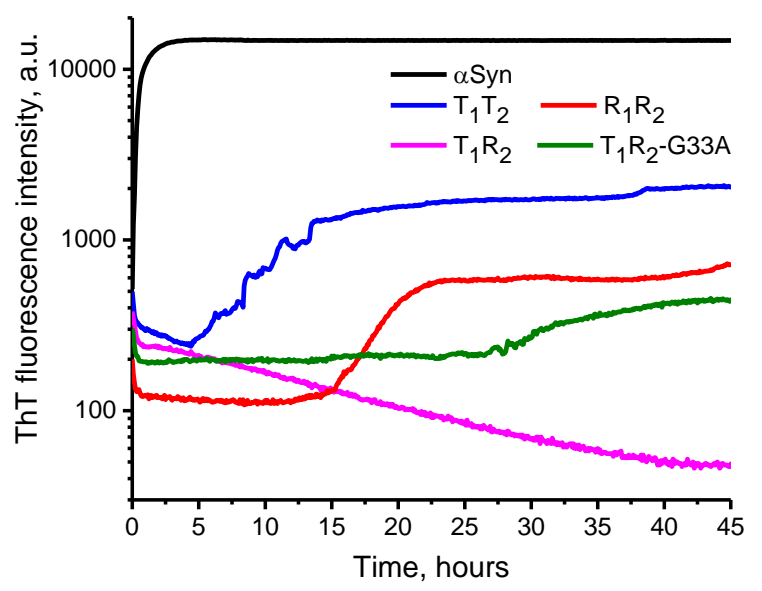

Fig. S14. Kinetics of fibrillization of $T_{1} T_{2}, R_{1} R_{2}, T_{1} R_{2}$ and $T_{1} R_{2}-G 33 A(40 \mu M)$, as well as $\alpha$ Syn $(40 \mu M)$ in the presence of $1 \mu \mathrm{M} \alpha$ Syn seeds monitored by ThT fluorescence increase. Logarithmic scale.

$T_{1} T_{2}, R_{1} R_{2}$, and $T_{1} R_{2}$-G33A slowly self-aggregate upon shaking, while $T_{1} R_{2}$ has shown no aggregation propensity (see Fig. S14). $\mathrm{T}_{1} \mathrm{R}_{2}$ inhibitor and its Pro and Cys mutants do not fibrillize at the room temperature or $37^{\circ} \mathrm{C}$ even if seeded by $\alpha$ Syn fibrils. None of the $T_{1} R_{2}$ derivatives aggregate in high concentrations $(50-100 \mu \mathrm{M})$ during storage at $-20^{\circ} \mathrm{C}$ and several defreezing cycles.

Several freezing-defreezing cycles lead to the decrease in $T_{1} T_{2}$ and $R_{1} R_{2}$ concentration (due to the aggregates sedimentation), until protein concentration reaches about $5 \mu \mathrm{M}$ (in this concentration proteins do not aggregate at all). $T_{1} T_{2}, R_{1} R_{2}$ storage at the room temperature or at $4^{\circ} \mathrm{C}$ does not lead to the fibrillization ( 3 days, concentrations up to $40 \mu \mathrm{M}$ ), although $12 \mathrm{~h}$ shaking at the room temperature does. Therefore, during purification, conditions of digestion of SUMO-tag with protease for $T_{1} T_{2}$ and $R_{1} R_{2}$ were optimized for only $1 \mathrm{~h}$ shaking. 


\section{S16. Absorption and emission spectra of FRET pair dyes}

In this work $\alpha$ Syn linked via maleimide linker with labels was used for the detection of aggregated $\alpha$ Syn in cells. For the visualization of the protein aggregates inside cell, FRET pair of ATTO565 and ATTO647 labels was used (Fig. S15 A). FRET occurs upon the fibrillization of the labelled $\alpha$ Syn (mixture of $\alpha$ Syn-ATTO565 $(11 \mu \mathrm{M})$ and $\alpha$ Syn-ATTO647 $(11 \mu \mathrm{M})$ in solution after the seeds addition (Fig. S15 B, C).
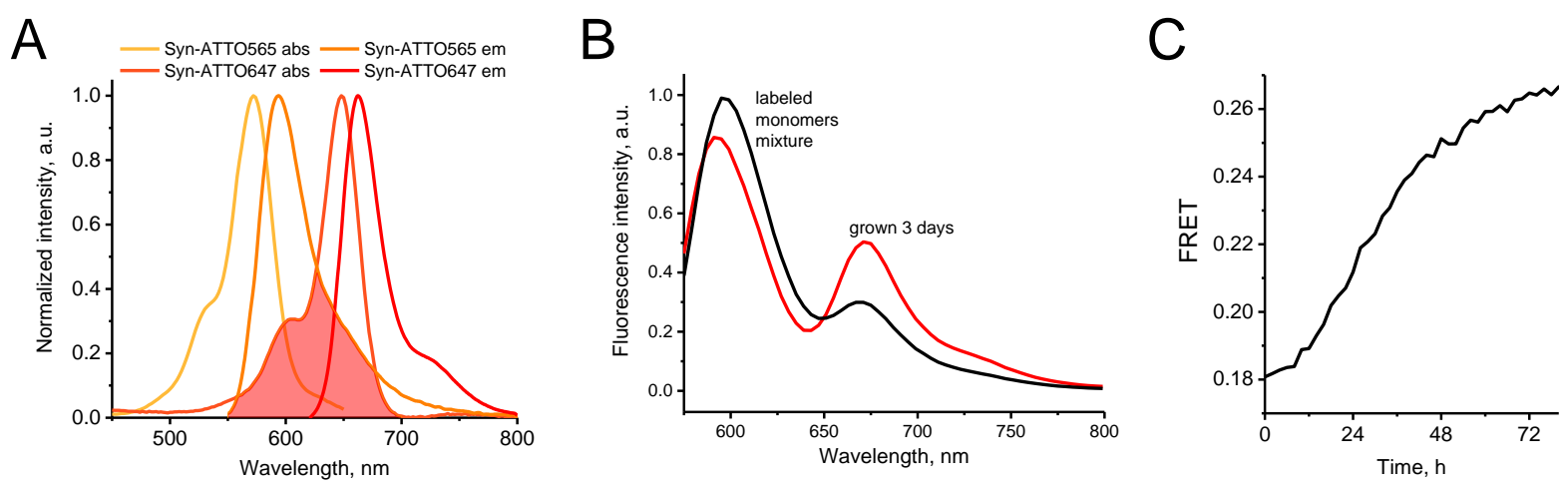

Fig. S15. A) Absorption and emission spectra of aSyn, labelled with ATTO565 and ATTO647 dyes. B) Fluorescence emission spectra of the 1:1 mixture of aSyn-ATTO565 and aSyn-ATTO647 before fibrillization (black) and after 3 days of incubation in the presence of $0.5 \mu \mathrm{M}$ seeds. Total concentration of the $\alpha$ Syn was $22 \mu \mathrm{M}$. $\lambda_{\mathrm{ex}}=550 \mathrm{~nm}$. C) Change in the FRET efficiency upon the fibrillization calculated as $\mathrm{I}_{690} /\left(\mathrm{I}_{595}+\mathrm{I}_{690}\right)$ based on the spectra presented in panel B. 


\section{S17. Control of the purity of inhibitors}

Purity of the obtained inhibitors was checked by HPLC using Watrex $250 \times 4 \mathrm{~mm}$ C8 (p.s.5 $\mu \mathrm{m}$ ) reverse phase column using DeltaChrom system (Watrex). Proteins were eluted using a linear acetonitrile-water gradient (0-90\% in $30 \mathrm{~min}), 0.1 \%$ trifluoroacetic acid, at the flow rate of $0.75 \mathrm{ml} / \mathrm{min}$ and monitored by absorption at $220 \mathrm{~nm}$ (absorption of peptide bonds).
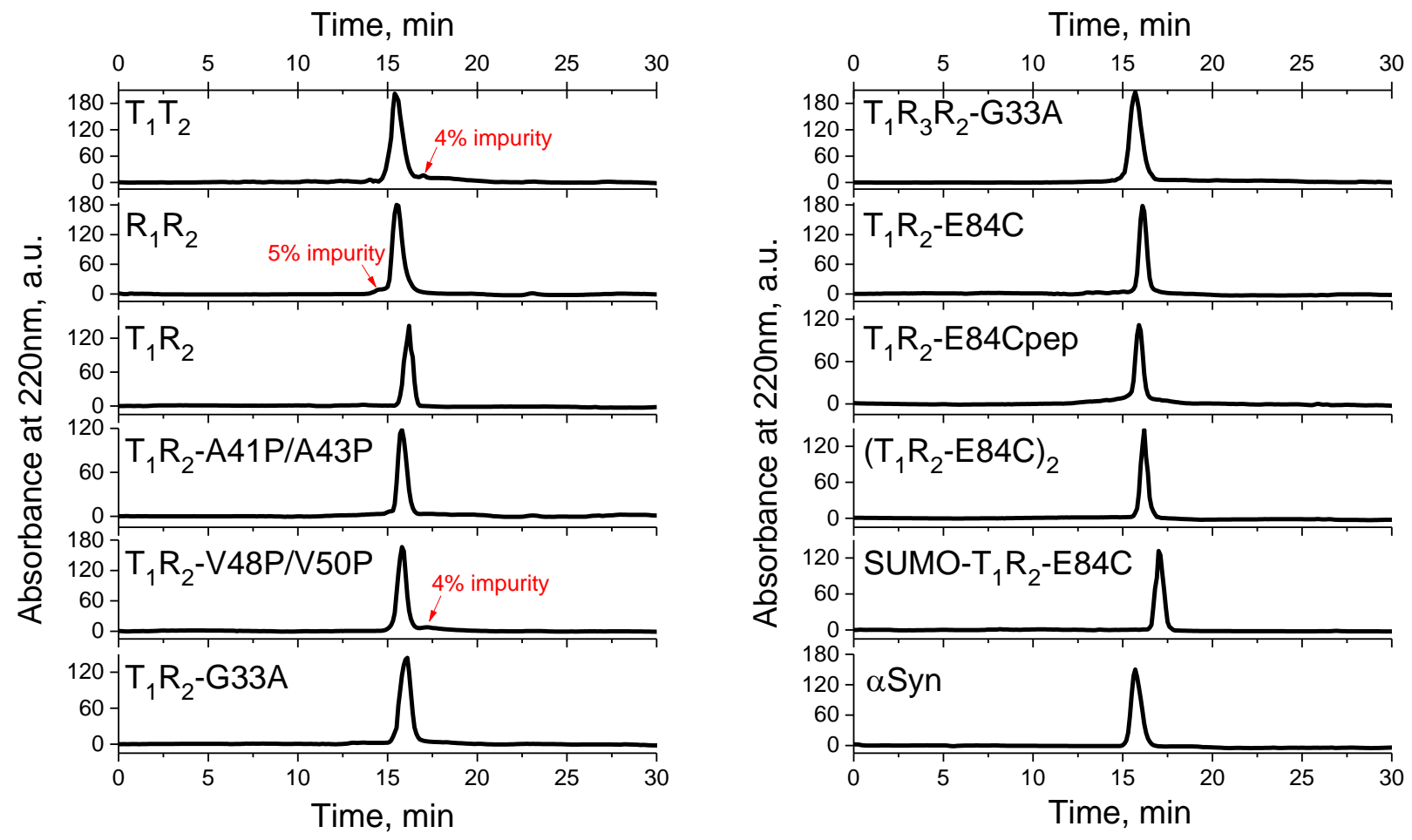

Fig. S16. Chromatograms of the inhibitors and $\alpha$ Syn. Impurities present in $T_{1} T_{2}, R_{1} R_{2}$ and $T_{1} R_{2-}$ V48P/V50P are likely proteins incomplete or alternative protease cleavage. 


\section{S18. Assessment of cell penetration of inhibitor and $\alpha$ Syn}

To test the ability of small pre-formed fibrils (seeds) to penetrate cell plasma membrane (PM) and accumulate inside cells, where further they will induce $\alpha$ Syn fibrillization, we used seeds prepared from a mixture of $90 \%$ wt $\alpha$ Syn and $10 \%$ of SRhB-labeled $\alpha$ Syn-A18C. HeLa cells were plated on a Lab-Tek Chamber Slide $24 \mathrm{~h}$ prior to the incubation. After that, $2 \mu \mathrm{M} \alpha$ Syn seeds were added to the cells and incubated for $24 \mathrm{~h}$. Then cells were washed, stained with ConA-FITC PM tracker and visualized using confocal microscopy. Significant amount of $\alpha$ Syn seeds was observed inside the cells, indicating that seeds are able to penetrate cell membrane (Fig. S17A, B).

The ability of the monomeric $\alpha$ Syn to penetrate into cells was confirmed by the similar experiment, by imaging cells that were incubated with the 600nM SRhB-labeled $\alpha$ Syn-A18C (Fig. S17C). $\alpha$ Syn monomer and seeds localize in same cellular compartments (Fig. S17D).
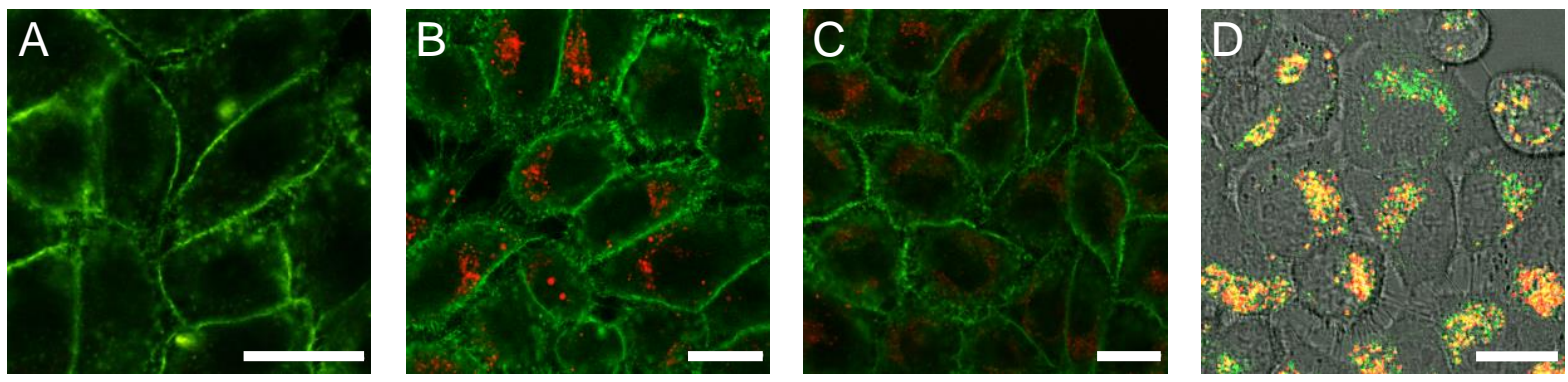

Fig. S17. HeLa cells after $24 \mathrm{~h}$ of incubation with buffer (A), SRhB-labeled $\alpha$ Syn seeds (B) or SRhBlabeled $\alpha$ Syn-A18C (C). Fluorescence from PM tracker is shown in green, signal from ShRB label is shown in red. D. HeLa cells after $24 \mathrm{~h}$ of incubation with SRhB-labeled $\alpha$ Syn seeds (shown in red) and ATTO488labeled $\alpha$ Syn-A18C (shown in green). Scale bars are $20 \mu \mathrm{m}$.

The ability of inhibitors to cross cellular membrane was checked in a similar way. HeLa cells, grown on a Lab-Tek Chamber Slide, were incubated with $1 \mu \mathrm{M} \mathrm{T} \mathrm{T}_{1}$-E84C-Mal-ShRB for $24 \mathrm{~h}$, washed, stained with PM tracker and visualized. Fluorescence of the labelled protein was observed in cells after incubation (Fig. S18B), which confirmed its accumulation inside the cells. In the similar experiment, where Lysotracker was used to stain lysosomes, the fraction of the inhibitor that is not colocalized with lysosomes can be seen (Fig. S18A).

To assess inhibitor's toxicity, following assay was performed: HeLa cells were plated in 96-well plates at 10000 cells per well in complete cell growth media and incubated for $24 \mathrm{~h}$ in an incubator with $5 \% \mathrm{CO}_{2}$ at $37^{\circ} \mathrm{C}$. After incubation the cells were treated with different concentrations of $\mathrm{T}_{1} \mathrm{R}_{2}-\mathrm{E} 84 \mathrm{C}$ protein for $24 \mathrm{~h}$. Next, cell media was exchanged with a fresh one and Presto Blue cell toxicity reagent (A13261, Thermofisher Scientific, Prague) was added according to the manufacturer's instructions followed by $1 \mathrm{~h}$ incubation. Presto Blue fluorescence was quantified at the respective excitation and emission wavelengths of 560 and $590 \mathrm{~nm}$ using a Tecan Spark microplate reader. Background signal (measured from wells containing only cell media and the Presto Blue solution) was subtracted and then the data was normalized to the signal from cells treated with buffer without inhibitor (set as $100 \%$ vitality value). The $\mathrm{T}_{1} \mathrm{R}_{2}-\mathrm{E} 84 \mathrm{C}$ protein showed no toxicity in concentrations up to $1 \mu \mathrm{M}$ (Fig. S18C) that is 50 -fold higher than the concentrations used in our work. 

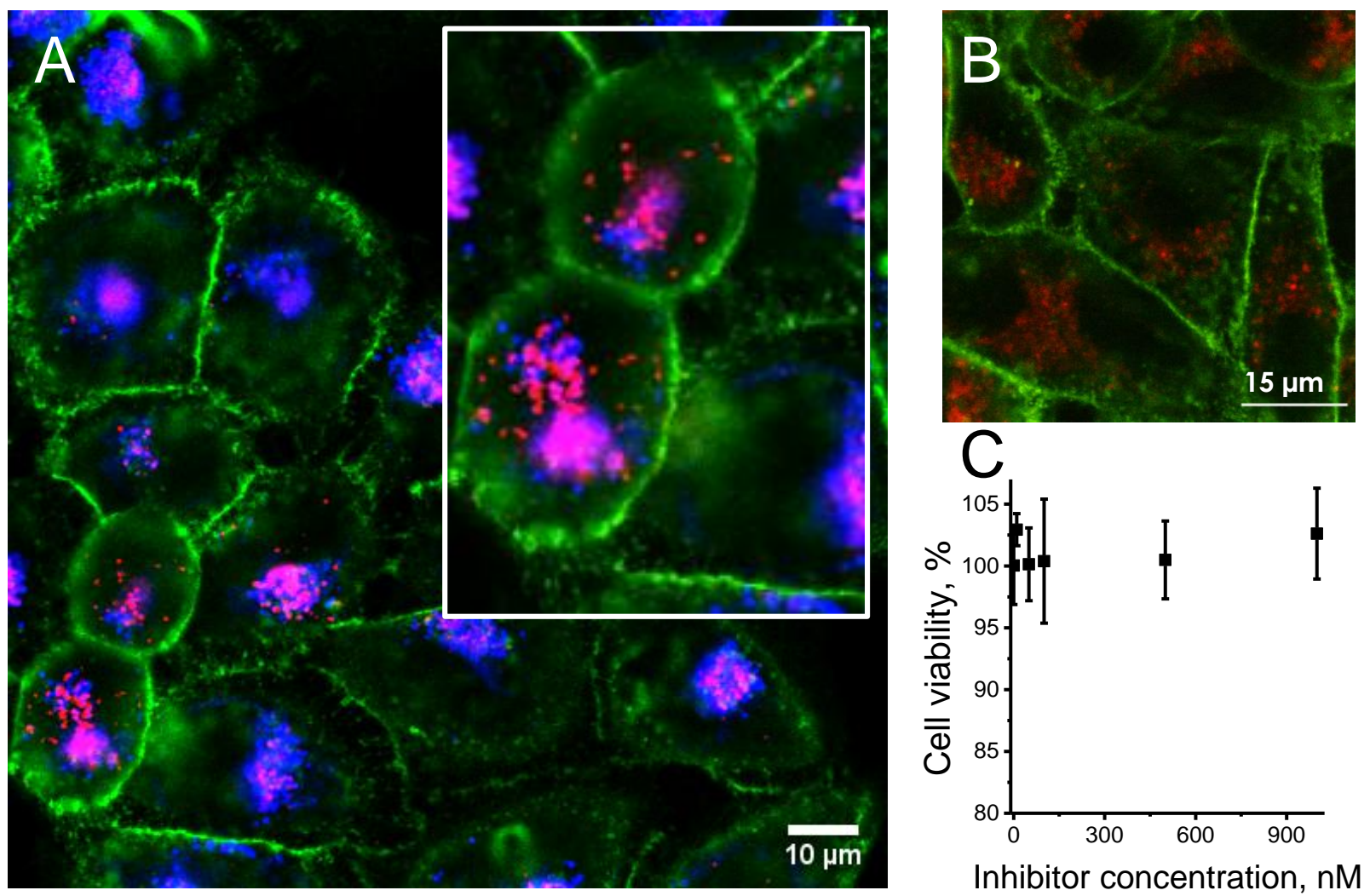

Fig. S18. HeLa cells after $24 \mathrm{~h}$ of incubation with $\mathrm{T}_{1} \mathrm{R}_{2}$-E84C-Mal-SRh B inhibitor $(2 \mu \mathrm{M}$ in $\mathrm{A}, 1 \mu \mathrm{M}$ in B). Fluorescence from PM tracker is shown in green, signal from ShRB label is shown in red, Lysotracker Deep Red is in blue. Red dots clearly visible in zoomed area are inhibitor fraction not colocalized with lysosomes. C) Cell viability after incubation with different concentrations of $\mathrm{T}_{1} \mathrm{R}_{2}-\mathrm{E} 84 \mathrm{C}$. 


\section{S19. Assessment of the $\alpha$ Syn fibrillization in cells}

\section{Aggregation in SH-SY5Y cells}
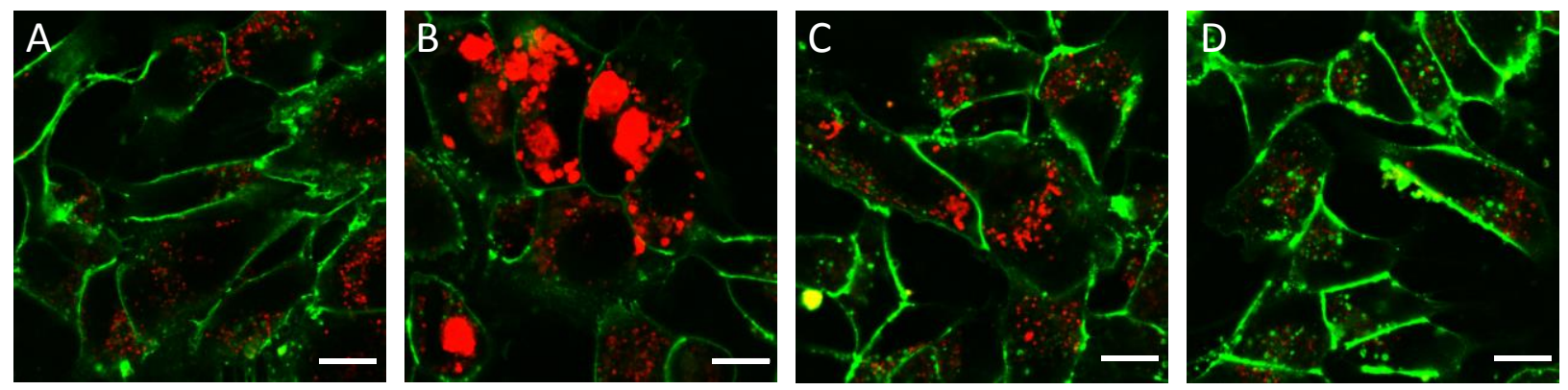

Fig. S19. Inhibition of $\alpha$ Syn aggregation in SH-SY5Y cells. SH-SY5Y cells incubated for $24 \mathrm{~h}$ with $400 \mathrm{nM}$ $\alpha$ Syn (1:1 mixture of ATTO565 and ATTO647 labeled proteins), without seeds and inhibitor (A), pretreated with $1 \mu \mathrm{M}$ seeds (B), and pretreated with seeds and incubated with $20 \mathrm{nM}(\mathrm{C})$ or $100 \mathrm{nM}$ of $\mathrm{T}_{1} \mathrm{R}_{2}$-E84C (D). PM-tracker $(\lambda \mathrm{ex}=488 \mathrm{~nm}, \lambda \mathrm{em}=500-550 \mathrm{~nm}$ ) is shown in green and FRET signal from labeled $\alpha$ Syn is shown in red $(\lambda e x=565 \mathrm{~nm}, \lambda \mathrm{em}=630-745 \mathrm{~nm})$. $\alpha$ Syn aggregates can be recognized as bright, dense inclusions in cells. Scale bar is $10 \mu \mathrm{m}$. Experiments were performed similarly to experiments with HeLa cells shown in Fig. 6.

\section{Aggregation in HeLa cells}

To pick the optimal conditions for the plate-reader based assay, we monitored kinetics of $\alpha$ Syn fibrillization in cells in the absence of inhibitor and in the presence of 20 and $100 \mathrm{nM} \mathrm{T} \mathrm{T}_{2}-\mathrm{E} 84 \mathrm{C}$. HeLa cells, grown on a Lab-Tek Chamber Slide, were incubated with $1 \mu \mathrm{M}$ non-labeled seeds overnight. Then the cells were washed and incubated for $8 \mathrm{~h}$ in complete media and treated with $400 \mathrm{nM}$ of the 1:1 mixture of fluorescently labeled $\alpha$ Syn ( $\alpha$ Syn-9C-ATTO647 and $\alpha$ Syn-9C-ATTO565) and different concentrations of $\mathrm{T}_{1} \mathrm{R}_{2}$-E84C inhibitor $(0,20$ or $100 \mathrm{nM})$. After the incubation for 3/12/24/48 h the cells were washed, stained with PM tracker, and imaged (Fig. S20). For the further measurements of the inhibitor activity incubation for $24 \mathrm{~h}$ was chosen. For each tested inhibitor three independent tests were performed with 6-7 different inhibitor concentrations (in 6-8 repeats each) and two controls: negative (no seeds added, but cells were treated with monomer) and positive (monomer and seeds were added to cells, no inhibitor). For each control 12 repeats were done. Raw data for one test for each inhibitor are presented in Fig. S21. 


\section{Aggregation of $\alpha$ Syn inside HeLa cells}
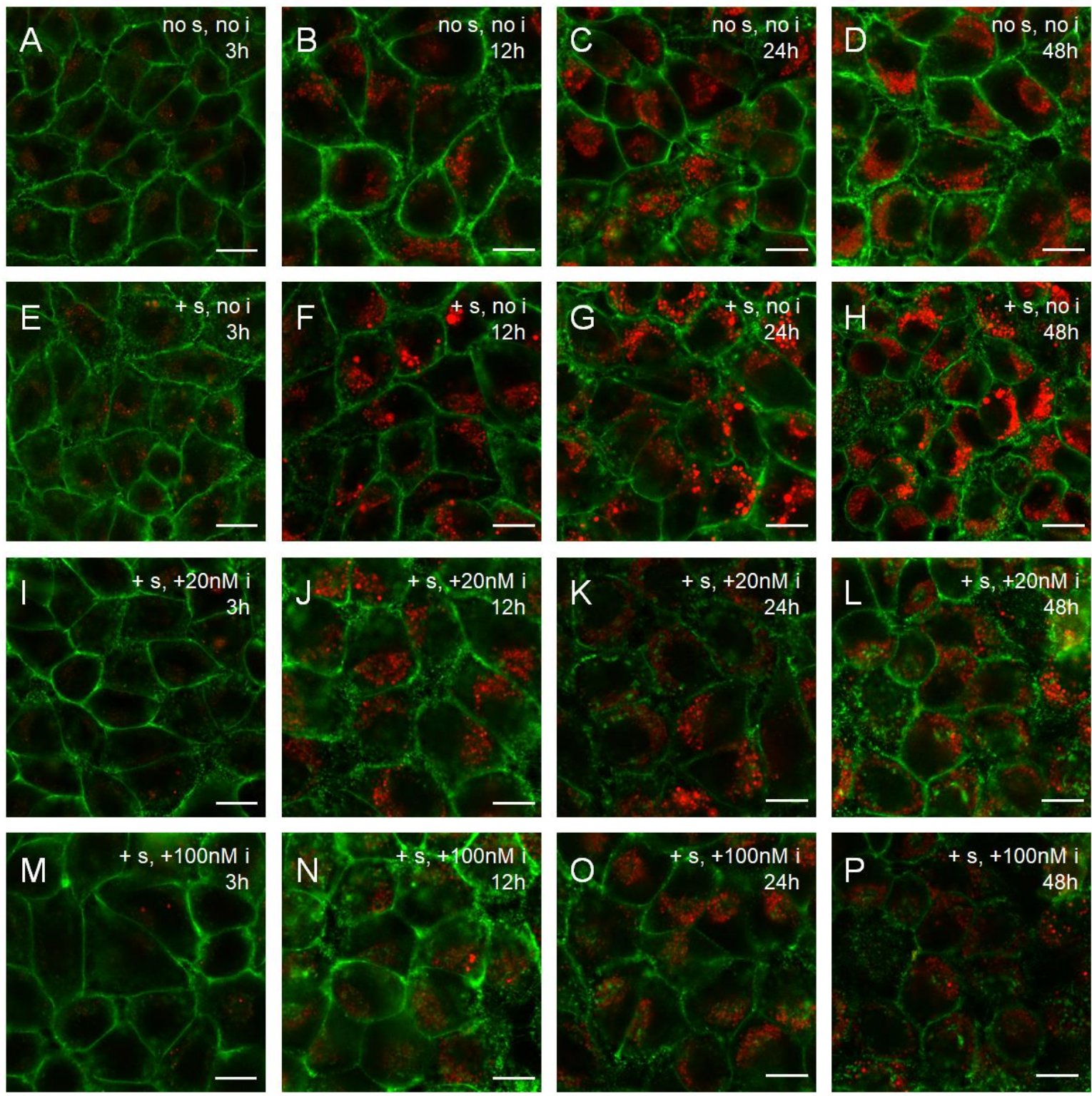

Fig. S20. Time dependency of $\alpha$ Syn aggregation in HeLa cells under different conditions. HeLa cells were incubated with labeled $\alpha$ Syn monomers. Pictures were made after $3 \mathrm{~h}(\mathrm{~A}, \mathrm{E}, \mathrm{I}, \mathrm{M}), 12 \mathrm{~h}(\mathrm{~B}, \mathrm{~F}, \mathrm{~J}, \mathrm{~N}), 24 \mathrm{~h}$ $(\mathrm{C}, \mathrm{G}, \mathrm{K}, \mathrm{O})$ and $48 \mathrm{~h}(\mathrm{D}, \mathrm{H}, \mathrm{L}, \mathrm{P})$ of incubation. In A-D HeLa cells were incubated with labeled monomers only. In E-P cells were pretreated with $1 \mu \mathrm{M}$ seeds (s) and then incubated with $\alpha$ Syn monomers together with buffer (E-H), $20 \mathrm{nM}$ (I-L) or $100 \mathrm{nM}(\mathrm{M}-\mathrm{P})$ of $\mathrm{T}_{1} \mathrm{R}_{2}$-E84C inhibitor (i). PM-tracker is shown in green and collected FRET signal is shown in red. $\alpha$ Syn aggregates can be recognized as bright, dense inclusions in cells. Scale bar is $20 \mu \mathrm{M}$. 


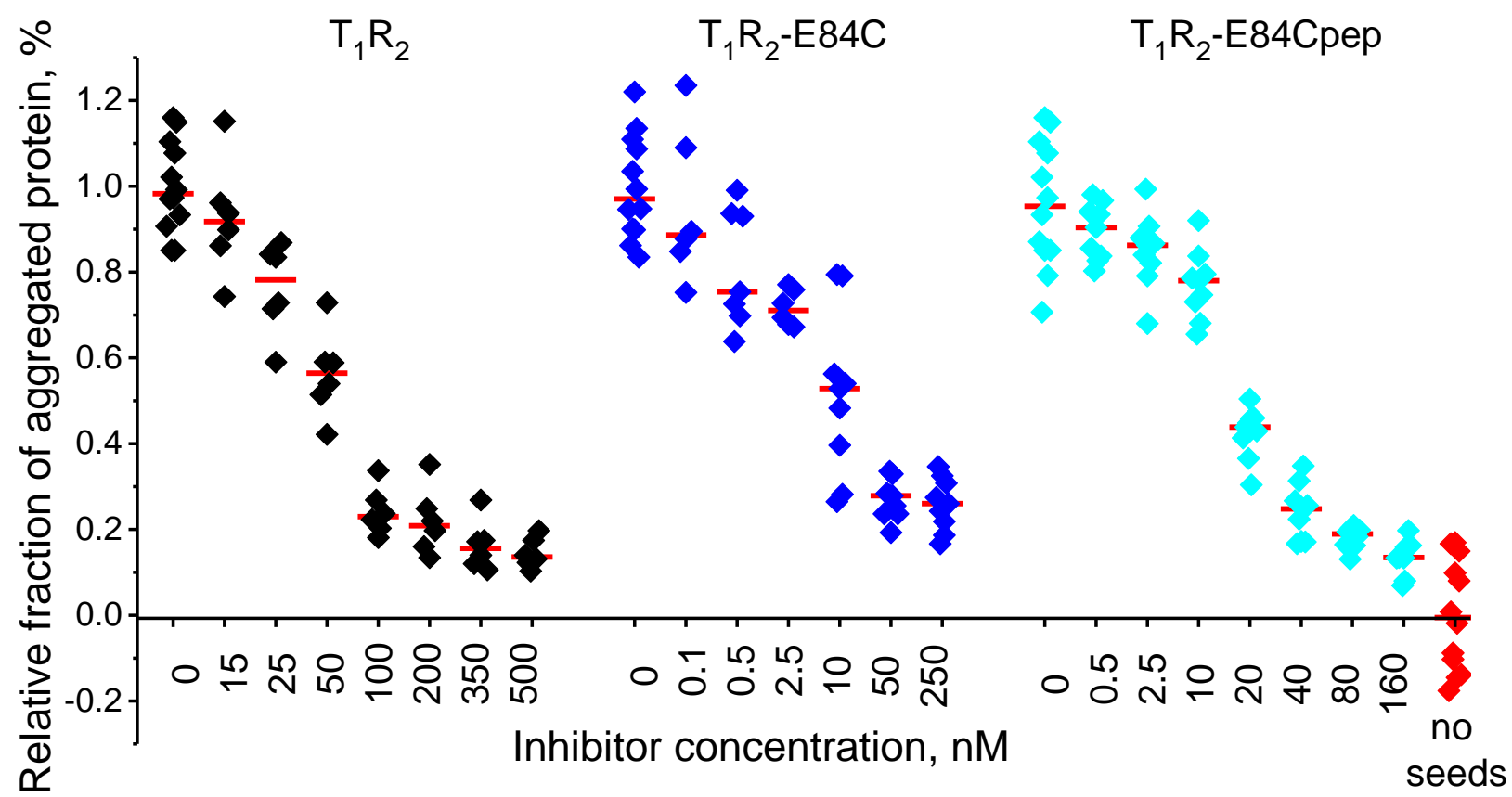

Fig. S21. Relative fraction of aggregated $\alpha$ Syn at different inhibitor concentrations measured in HeLa cells

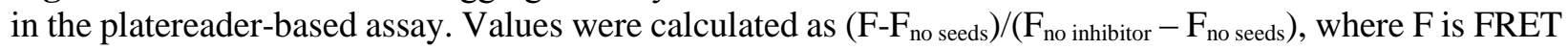
signal at given inhibitor concentration. Concentration of monomeric $\alpha$ Syn $(1: 1$ mixture of SRhB- and ATTO647-labeled) added to cells was $600 \mathrm{nM}$. Seeds were $1 \mu \mathrm{M}$. $\lambda$ ex $=550 \mathrm{~nm}$, $\lambda \mathrm{em}=650 \mathrm{~nm}$, slits $=20 \mathrm{~nm}$. Experimental points from individual wells of one typical experiment out of three from Fig.6D are shown. 


\section{References}

(1) Afitska, K.; Priss, A.; Yushchenko, D. A.; Shvadchak, V. V., Structural optimization of inhibitors of $\alpha$-synuclein fibril growth: Affinity to the fibril end as a crucial factor. $J$ Mol Biol 2020, 432, 967-977.

(2) Li, B.; Ge, P.; Murray, K. A.; Sheth, P.; Zhang, M.; Nair, G.; Sawaya, M. R.; Shin, W. S.; Boyer, D. R.; Ye, S., et al., Cryo-EM of full-length $\alpha$-synuclein reveals fibril polymorphs with a common structural kernel. Nat Commun 2018, 9, 3609.

(3) Li, Y.; Zhao, C.; Luo, F.; Liu, Z.; Gui, X.; Luo, Z.; Zhang, X.; Li, D.; Liu, C.; Li, X., Amyloid fibril structure of $\alpha$-synuclein determined by cryo-electron microscopy. Cell Res 2018, 28, 897-903.

(4) Rodriguez, J. A.; Ivanova, M. I.; Sawaya, M. R.; Cascio, D.; Reyes, F. E.; Shi, D.; Sangwan, S.; Guenther, E. L.; Johnson, L. M.; Zhang, M., et al., Structure of the toxic core of $\alpha$-synuclein from invisible crystals. Nature 2015, 525, 486-490.

(5) Guerrero-Ferreira, R.; Taylor, N. M.; Arteni, A. A.; Kumari, P.; Mona, D.; Ringler, P.; Britschgi, M.; Lauer, M. E.; Makky, A.; Verasdonck, J., et al., Two new polymorphic structures of human fulllength $\alpha$-synuclein fibrils solved by cryo-electron microscopy. eLife 2019, 8 .

(6) Sun, Y.; Hou, S.; Zhao, K.; Long, H.; Liu, Z.; Gao, J.; Zhang, Y.; Su, X. D.; Li, D.; Liu, C., Cryoem structure of full-length $\alpha$-synuclein amyloid fibril with parkinson's disease familial A53T mutation. Cell research 2020, 30, 360-362.

(7) Afitska, K.; Fucikova, A.; Shvadchak, V. V.; Yushchenko, D. A., $\alpha$-Synuclein aggregation at low concentrations. Biochim Biophys Acta Proteins Proteom 2019, 1867, 701-709.

(8) Shvadchak, V. V.; Afitska, K.; Yushchenko, D. A., Inhibition of $\alpha$-synuclein amyloid fibril elongation by blocking fibril ends. Angew Chem Int Ed Engl 2018, 57, 5690-5694. 